CUPAUAM 25.1, 1998, pp. 245-281

\title{
DATOS PARA LA DEFINICIÓN DE LA EDAD DEL HIERRO EN EL ÁMBITO CARPETANO: EL YACIMIENTO DE ARROYO CULEBRO ${ }^{[1]}$
}

\author{
$M^{a}$ CONCEPCIÓN BLASCO BOSQUED \\ Elena CarRión SANTEFE \\ Mercedes Planas GarRido \\ Departamento de Prehistoria y Arqueología \\ Universidad Autónoma de Madrid
}

\section{Resumen}

El trabajo da a conocer un yacimiento de la Edad del Hierro localizado en el entorno del Arroyo Culebro. Los datos que aporta marcan una nueva estrategia de poblamiento frente a las pautas del la Edad del Bronce pero evidencia una continuidad en la arquitectura doméstica efímera. Por primera vez se documenta en la Meseta Sur la inhumación de un neonato en el espacio doméstico, donde se habían practicado todos los enterramientos en épocas previas.

Los materiales cerámicos recuperados en este sitio son un buen exponente de la confluencia de tradiciones y de contactos e influencias que se producen en esta zona central de la Península y de fácil comunicación y permiten definir la personalidad del área carpetana en relación con los pueblos limítrofes.

\begin{abstract}
The paper is an approach of an Iron Age site located in the surroundings of the Culebro stream. The data indicates a new settlement strategy in contrary to the guidelines observed for the Bronze Age, but still shows a continuity of the ephemeral domestic architecture. It is documented for the first time in the South Meseta, the inhumation of a newborn in the domestic area where it would have been practiced all the burials in previous periods.

The ceranic materials recovered in this site are a good exponent of the traditions and contacts confluences, and also of the influences in this area of the central Peninsula of easy communication that allows to define the personality of the Carpetan area with regard to the neighbouring cultures.
\end{abstract}

[1] Este trabajo se inscribe en el marco del proyecto de Investigación subvencionado por el $\mathrm{MEC}, \mathrm{n}^{\circ}$ de referencia PB 96-0020 
En el transcurso de la realización de la Carta Arqueológica de Getafe se localizó el yacimiento denominado Arroyo Culebro, situado a la altura del kilómetro 9.400 derecha, de la carretera de San Martín de la Vega, dentro de la pedanía de Perales del Río (Getafe). Sus restos muebles se extendían por una amplia superficie de unas tres Ha. pero es muy probable que la intensa remoción realizada por las máquinas dedicadas a la extracción de áridos hubieran dispersado los materiales por un área algo más amplia que la del propio yacimiento, a ello se unía un arrasamiento previo, de buena parte de la superficie, afectada por el camino que, partiendo de la carretera de San Martín de la Vega, transcurre por un trazado paralelo al arroyo Culebro. Las características geográficas del sitio y de los materiales que ha entregado son representativas de la Edad del Hierro en este ámbito del que apenas existen estudios que permitan conocer su personalidad.

\section{LA LOCALIZACIÓN DEL YACIMIENTO}

El sitio se ubica en la segunda terraza de la margen derecha del río Manzanares y en la orilla izquierda del arroyo Culebro, a unos 4 kilómetros aguas arriba de la confluencia de ambos cauces y a una distancia de poco más de un kilómetro del lecho de estos dos cursos. Su situación le permite un control visual de las dos vegas que en esta zona debieron llegar a crear un amplio humedal de especial rendimiento tanto para pastizales como para la agricultura de regadío. Su ubicación en alto favorece no sólo el dominio de un amplio tramo del Manzanares, fundamental en las relaciones norte-sur, sino también el cauce del arroyo Culebro que permite las comunicaciones en sentido este-oeste poniendo en contacto las cuencas de los ríos Guadarrama y Manzanares. Prueba de su privilegiada ubicación en relación con las vías de la zona es su situación sobre la propia Cañada Real cuyo trazado sigue hoy el camino local que divide en dos el yacimiento.

Este emplazamiento representa un cambio sustancial con respecto a la localización preferida por los asentamientos que, desde el Neolítico, y a lo largo de toda la Edad del Bronce, poblaron las campiñas meridionales de Madrid. En efecto, desde inicios del IV milenio y hasta comienzos del I milenio a. C. la mayor parte de los lugares de hábitats madrileños se localizan en las terrazas bajas de los ríos principales y, preferentemente, en las proximidades a las desembocaduras de los cursos secundarios, donde hay un buen dominio de las tierras de vega pero sin control visual de los interfluvios. La novedad en las preferencias de los asentamientos de la Edad del Hierro puede estar relacionada con la voluntad de evitar los lugares previamente habitados, la necesidad de dominar los pasos y vías de comunicaciones, la búsqueda de los páramos interfluviales para obtener un mayor control visual de ciertas rutas, facilitando los intercambios y/o la puesta en cultivo de tierras de secano, ya que, pese a esta posición más dominante, las necesidades de defensa no parecen haber sido las prioritarias pues siguen siendo lugares abiertos y sin ningún tipo de obra antrópica que mejore las escasas condiciones naturales de defensa del terreno. Una circunstancia que puede quedar modificada, si. técnicas de prospección, como la fotografía aérea consiguen documentar algún tipo de delimitación como empalizadas o fosos, similares a los que se han evidenciado en torno a algunos yacimientos calcolíticos y de la Edad del Bronce de la Meseta Norte. 
Estas características en el emplazamiento no son privativas del yacimiento que nos ocupa sino que es un rasgo común a una gran mayoría de los establecimientos de la Edad del Hierro. Concretamente, si nos ceñimos a los conocidos en la Cuenca Baja del Manzanares, encontramos diversos ejemplos de localización en alto, bien sea en Cerro, como el de San Antonio, bien en el borde de la terraza superior como Los Llanos o el propio de Arroyo Culebro, frente a ellos, existen algunos casos de ubicación en lugares llanos, cerca del río, como Puente de la Aldehuela, o más alejados, como La Capellana (Lámina 1), pero ninguno de ellos al borde de la terraza inferior, como había sido lo habitual en los sitios de horizontes previos, esta circunstancia lleva aparejado el alejamiento del río, por lo que, mientras la mayoría de los yacimientos del Horizonte Cogotas I se encuentran a unos 100/200 metros del cauce, los del Hierro suelen localizarse a algo más de un kilómetro, una diferencia que no es significativa para el territorio de explotación, que básicamente sigue siendo el mismo,

Un segundo rasgo destacable es su localización en la cuenca de un curso secundario, como es el Arroyo Culebro, aunque, en este caso concreto, se domine también el río principal: el Manzanares. Se trata, así mismo, de una circunstancia que comparten otros yacimientos de la Edad del Hierro, momento en el que parece producirse una cierta diversificación con la colonización de espacios nuevos, perdiéndose, en cierto modo, la disposición lineal en torno a los ríos principales para buscar la proximidad de cauces tributarios de menor entidad, transversales a aquéllos. En este caso, el yacimiento de Arroyo Culebro es uno más de los hábitats que encontramos en torno al curso secundario del mismo nombre, el más importante de los existentes en el curso inferior del Manzanares, en torno al cual se produce una cierta densidad de ocupación ya que en poco más de doce kilómetros se encuentran los sitios de Arenero de Salmedina, Aldehuela-Salmedina (Valiente, S. y Rubio, I., 1982), Puente de la Aldehuela (Priego , C. 1986), La Aldehuela (Valiente, S., 1973), Arroyo Culebro, La Zorrera, El Torrejón (Blasco C., Sánchez Capilla, Mª L. y Calle, J., 1988), La Capellana (Blasco, C. y Baena, J., 1989 y el Sector III de Getafe (Blasco, C. y Barrio J., 1986) entre otros. Desconocemos el por qué de este intenso poblamiento, pero entre otras razones, hay que considerar la circunstancia de que el Arroyo Culebro constituye una vía natural que pone en contacto las cuencas del Jarama y Manzanares con la del Guadarrama, sirviendo, por tanto, como un eje este-oeste entre los cursos fluviales principales que discurren en sentido norte-sur.

\section{CARACTERÍSTICAS DE LA OCUPACIÓN: CAMBIO Y CONTINUIDAD}

Esta nueva estrategia de poblamiento no es una tendencia local sino que responde a un fenómeno más general que abarca a otros puntos del interior peninsular y que además está ligado a una clara ruptura entre el poblamiento de la Edad del Bronce y el de la Edad del Hierro, abandonando los puntos en los que se habían fijado los poblados del III y el II milenio, algunos de ellos con abundantes reocupaciones, para buscar lugares ex novo, a veces situados a escasa distancia de los anteriores.

En cuanto a la duración de las ocupaciones de estos nuevos sitios, es muy desigual pues, mientras algunos de ellos son establecimientos bastante limitados en el tiempo, caso 


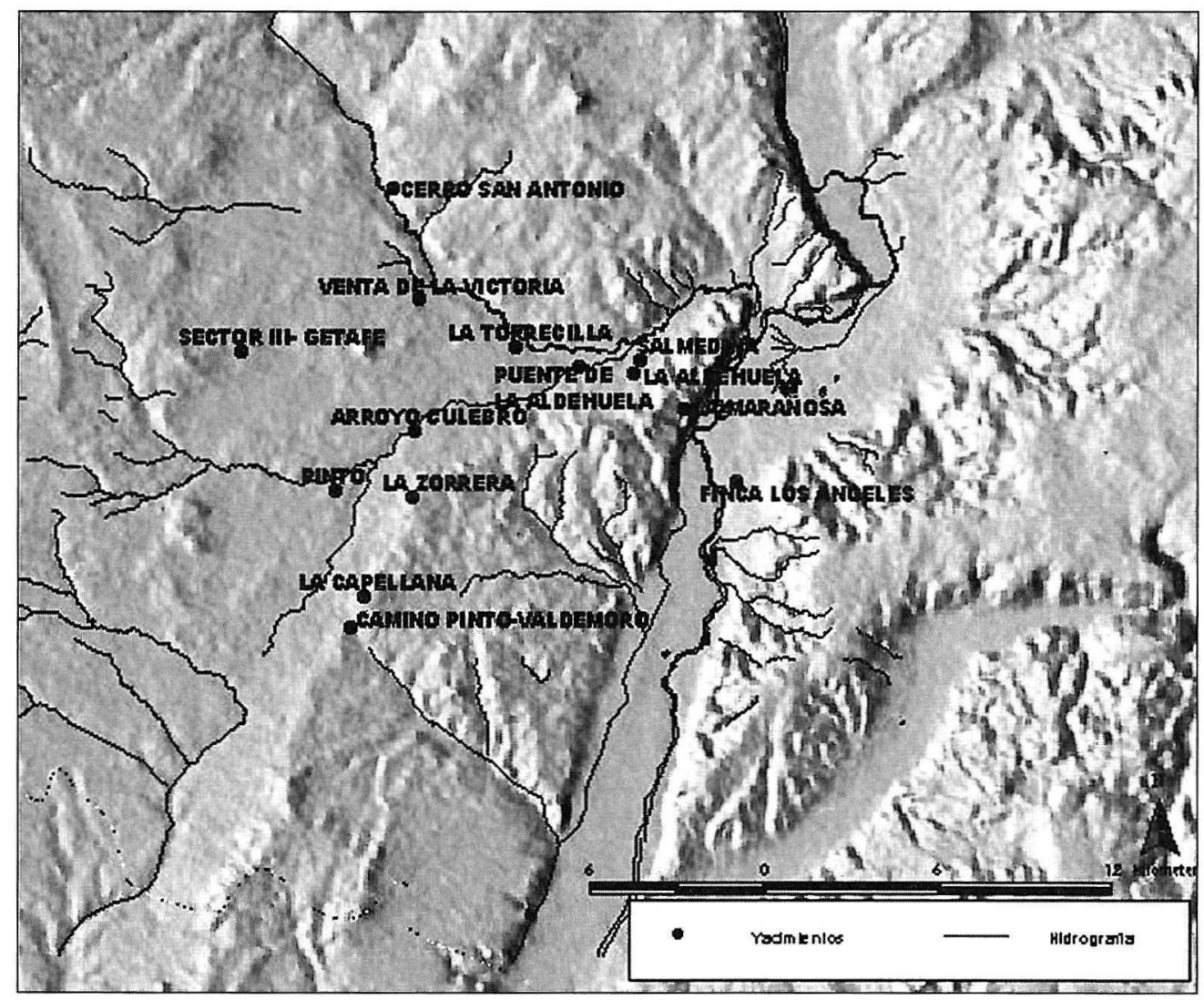

Lámina 1: Localización de los yacimientos de la Edad del Hierro en la cuenca baja del Manzanares.

de Cerro San Antonio, Sector III de Getafe o Los Llanos otros, como Puente de la Aldehuela o Arroyo Culebro, presentan indicios de haberse mantenido habitados de forma prolongada, no sabemos si con abandonos y reocupaciones o sin solución de continuidad. En todo caso las nuevas estrategias de poblamiento incluyen una mayor duración de las estancias, al menos, así parece desprenderse de la formación de suelos de ocupación, ausentes en los yacimientos del Horizonte Cogotas I y anteriores y de la aparente mayor envergadura de las estructuras, las cuales, cuando se han localizado, aparecen ligeramente excavadas en el subsuelo, para dotarlas de un mayor anclaje.

Tanto Puente de la Aldehuela como Arroyo Culebro, además de tener una cronología similar, presentan una extensión también muy parecida, unas $3 \mathrm{Ha}$., pero desconocemos la superficie total de cada uno de los establecimientos y la parte en la que se superponen. Sin embargo, teniendo en cuenta el tamaño de los yacimientos próximos con una única ocupación del Hierro I, como es el caso de Cerro de San Antonio o La Capellana, es probable que el asentamiento más antiguo no llegara a una hectárea mientras que la ocu- 
pación más reciente es la que abarcaría las tres Ha., extensión que, como en la Aldehuela, corresponde a la zona de máxima dispersión de los materiales.

En el yacimiento de Arroyo Culebro, no han podido recuperarse ni las posibles estructuras, ni la secuencia estratigráfica y potencia de los estratos debido al arrasamiento sufrido y al arrastre de los materiales a consecuencia de los trabajos de extracción de áridos, realizados con anterioridad a nuestra prospección. No obstante a tenor de la potencia y los rasgos que presentan los niveles geológicos en los que aparece el material mueble es posible que nos encontremos ante un yacimiento de características similares a las del cercano de Puente de la Aldehuela, que se localiza a tan sólo unos 2 kilómetros aguas abajo del arroyo Culebro el cual, aunque se encontraba también bastante afectado, todavía permitió una lectura estratigráfica, con dos niveles relativamente bien definidos y con un contexto arqueológico diferenciado: Uno, "superficial o de tierra vegetal", de entre 20 y 25 centímetros de espesor en el que apareció cerámica a torno y a mano, así como restos de materiales constructivos, básicamente ladrillos y adobes. La presencia de material arqueológico permitía pensar que en realidad este nivel integraría un "estrato delgado", correspondiente a una ocupación de la II Edad del Hierro prácticamente arrasado por el laboreo de la tierra. El nivel inferior se caracterizaba por ser de "tierra cenicienta gris-negra", con una potencia de unos 45 a 50 centímetros y en él aparecieron restos de pavimentos de grava, cerámica a mano, molinos barquiformes, fauna y adobes, todo ello, al igual que en el nivel superficial, muy fragmentado (Priego, C., 1986: 132).

Ambos yacimientos responden a lugares de nueva planta, dentro de un fenómeno generalizado en el Hierro antiguo, y ambos sitios se reocupan o simplemente se mantienen habitados durante un lapso temporal relativamente prolongado dentro ya de la Segunda Edad del Hierro, pero desgraciadamente nos faltan datos para determinar si existe o no un abandono entre los dos horizontes documentados (Hierro I y II). Frente a este tipo de yacimientos con presencia de materiales del Hierro Antiguo y de la Segunda Edad del Hierro, a los que podemos sumar otros ejemplos como La Aldehuela-Salmedina, existen otros establecimientos con ocupaciones puntales, exclusivamente del Hierro Antiguo, de escasa extensión y potencia que parecen mantener unas pautas más próximas a las de la Edad del Bronce, es el caso de sitios como Cerro San Antonio, Sector III de Getafe o La Capellana, todos ellos de reducidas dimensiones y más alejados de los cursos fluviales, lo que quizás impediría la estabilidad que se observa en los lugares mejor situados para el abastecimiento de agua.

\section{LA ARQUTTECTURA}

Entre los datos conocidos y más expresivos de la arquitectura de este horizonte hay que destacar los proporcionados por el yacimiento de la Dehesa (Alcalá de Henares) situado en la vega del Henares donde las cabañas, además de estar semiexcavadas, como es habitual, aparecen rodeadas por postes de buen tamaño que debieron de proporcionar una importante envergadura, esta técnica constructiva es propia tanto del Hierro Antiguo, como de la Segunda Edad del Hierro, un dato que podría explicar la ausencia de materiales cons- 
tructivos sólidos, en Arroyo Culebro y en Puente de la Aldehuela. Lo cierto es que en esta región del Tajo, salvo excepciones como la del Cerro Redondo, fechado a partir de finales del siglo $\mathrm{V}$ a. C., con una arquitectura de plantas regulares y lienzos de adobes de gran tamaño (Blascó, C. y Alonso, 1985), se mantiene, a lo largo de toda la Edad del Hierro, un tipo de arquitectura bastante efímera, a base de sustentación de madera y paramentos de barro, que apenas deja huellas

La morfología de las pocas cabañas de la Edad del Hierro conocidas, es propia de estructuras exentas que dejan vacíos más o menos amplios y que, en algunos casos, pueden estar parcialmente ocupados por subestructuras como hogares, hornos o silos. Este tipo de urbanismo oportunista, cuyos elementos se van incorporando a medida que surgen las necesidades, puede dar lugar a yacimientos de una extensión relativamente importante para el número de unidades existentes, por lo que el tamaño de la superficie ocupada no es, forzosamente, sinónimo de grupos de gran tamaño, aunque sí se produce un incremento, tanto de la extensión de los yacimientos, como del tamaño de los grupos a partir de la segunda Edad del Hierro, lo que explicaría que en Arroyo Culebro los materiales del Hierro Antiguo aparezcan sólo en una zona bastante limitada, mientras los pertenecientes a la Segunda Edad del Hierro se encuentren dispersos por una superficie más amplia.

Entre los restos descontextualizados que pudimos llegar a documentar no aparecieron ni sillares, ni grandes adobes, ni gruesos manteados con improntas vegetales, pero desconocemos si existió un aparejo de calizas y/o nódulos de sílex sin modificar, semejante al empleado en otras construcciones de la zona, incluso de épocas muy posteriores, como en la cercana villa romana de La Torrecilla (Blasco y Lucas, 2000) que pudo dispersarse antes de nuestra intervención. Posiblemente nos encontremos ante un tipo de arquitectura bastante efímera, como la documentada en otros yacimientos de la Edad del Hierro en la zona (Muñoz, K. y J Ortega 1996), que tan sólo se diferencia de las cabañas de la Edad del Bronce en la elaboración de un zócalo de unos 20 centímetros excavado en el suelo que, proporcionaría mayor estabilidad a la cabaña, la cual, sólo en algunas zonas, tendría suelos de guijarros o de tierra más compactada a los que seguramente corresponden algunos indicios de concentraciones de pequeñas piedras y manteados de barros localizados en la Cuadrícula T1 (Lámina 2, $\mathrm{n}^{\circ} 2$ ), el único punto excavado donde parece que la remoción era menor.

\section{INHUMACIÓN INFANTIL EN EL ESPACIO DOMÉSTICO, UNA EVIDENCIA ESPERADA}

Precisamente la mejor conservación del yacimiento en la superficie de la cuadrícula T1 ha permitido obtener un dato de interés a partir de uno de los hallazgos más significativos: La conservación de parte del esqueleto de un individuo perinatal (Lámina $2, \mathrm{n}^{\circ} 1$ ) del que se recuperaron los dos fémures, un húmero, los dos radios y una costilla. Estos restos deben de interpretarse como procedentes de un enterramiento junto o bajo el suelo de una de las viviendas, normalmente, bajo la zona más interior de las habitaciones, en un lugar alejado de la luz solar. Se trata de una práctica bien conocida en la Península, tanto en el ámbito ibérico como en el Valle del Ebro y la Meseta Norte y cuya tradición parece iniciarse 


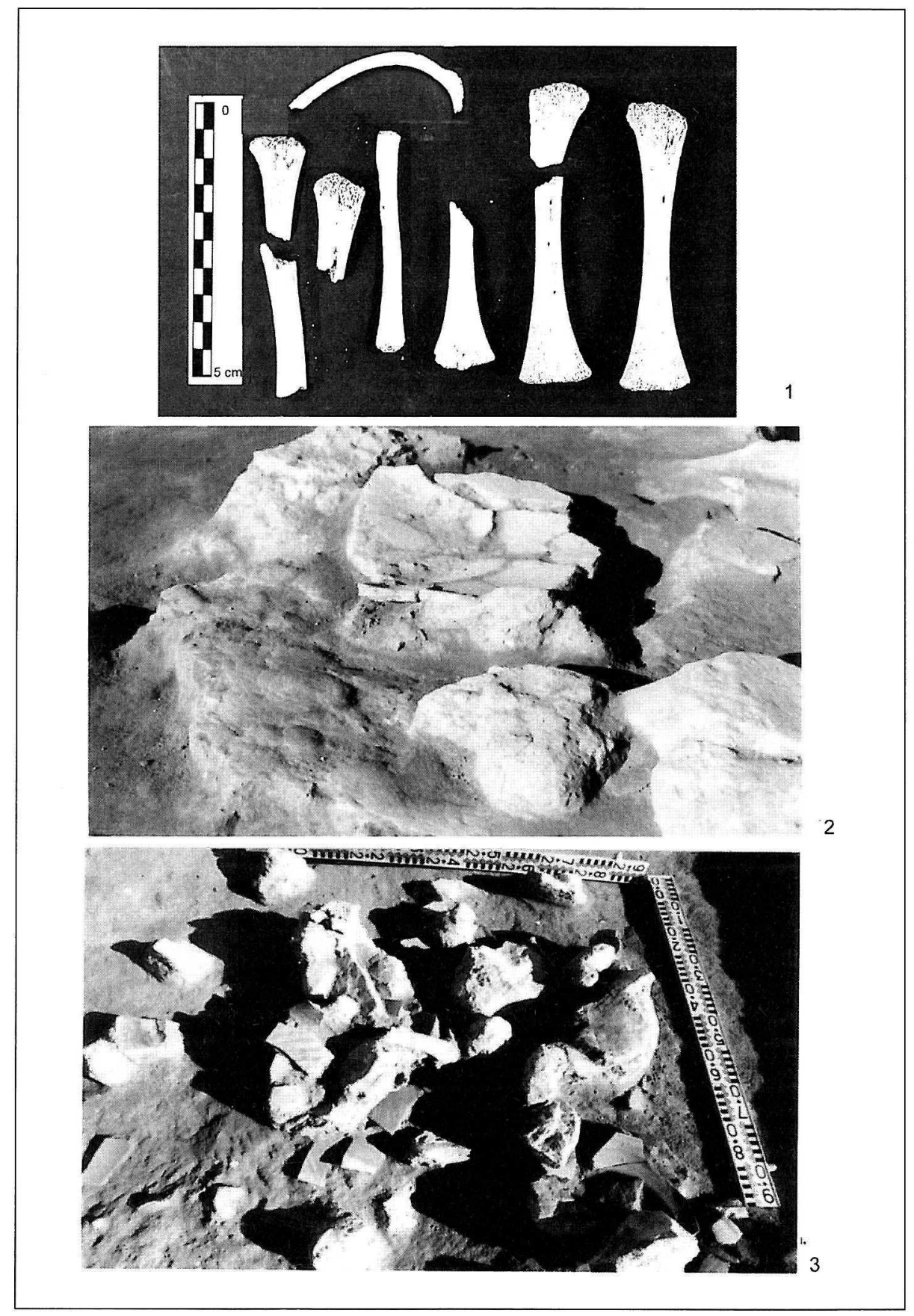

Lámina 2: 1: Esqueleto parcial de un perinatal aparecido bajo un pavimento en el yacimiento de Arroyo Culebro. 2 y 3: Restos de suelos y del posible paramento de una habitación. 
en la I Edad del Hierro (Agustí, B. y otros, 2000), aunque se generaliza hacia el siglo V, momento al que pertenecen un importante número de hallazgos (Barrio, J. 1999: 191-194) y en el que podemos enmarcar también éste de Arroyo Culebro. A pesar de las numerosas muestras de esta práctica, hasta ahora no se conocía ningún caso en la Meseta Sur, por lo que el hallazgo viene a cubrir un vacío que, en principio, no tenía explicación, pues a medida que vamos teniendo datos sobre las prácticas funerarias en esta zona, se confirma una cierta uniformidad con las de otros pueblos peninsulares.

Según Manuel Pérez Martín, de la Unidad de Antropología de la UAM, el tamaño de los huesos hace pensar en un perinatal, de unos nueve meses de vida intrauterina, corroborando la costumbre observada en otros yacimientos de que posiblemente sólo los menores de seis meses eran enterrados bajo el espacio doméstico mientras que desde esa edad y hasta los dos años eran inhumados, pero ya en las necrópolis, junto a las incineraciones de los adultos (Barrio, J. 1999:193). La debilidad de los huesos de los infantes de tan corta edad, unida a su presencia bajo los suelos, sin una protección especial, pueden ser las causas de que muchas veces no se conserven o, simplemente no se identifiquen, por lo que hay que pensar que estas deposiciones serían mucho más frecuentes que los casos conocidos y, por tanto no tendrían el carácter de excepcionalidad que se les ha atribuido en algunos casos.

Algunas de las explicaciones barajadas sobre el significado de estas inhumaciones se encuentran en la ritualización del infanticidio vinculado a los sacrificios fundacionales, ofrenda de primicias, la muerte prematura antes de la filiación, pasando por el infanticidio como procedimiento de control demográfico (Agustí, B. y otros, 2000: 318-320), pero nos faltan datos para confirmar cualquiera de estas hipótesis. No obstante, no puede olvidarse que la práctica de enterramientos en el espacio doméstico, tanto para adultos como para niños, fue una práctica generalizada durante la Edad del Bronce ya que la idea de necrópolis como espacio reservado a los muertos se difumina a partir del megalitismo, permaneciendo sólo entre algunos grupos campaniformes, de manera que a lo largo del II milenio, en estas tierras del interior peninsular vivos y muertos comparten un mismo espacio: bien sea en el interior de las motillas, de los poblados fortificados, o de los poblados abiertos ribereños, por lo que estas inhumaciones infantiles son herederas de una tradición ampliamente arraigada.

\section{LOS MATERIALES MUEBLES}

En la mayoría de los yacimientos de este Horizonte, los enseres recuperados son relativamente modestos ya que están constituidos por fragmentos cerámicos que generalmente no permiten la reconstrucción completa de los recipientes; a ellos se suman algunas piezas líticas de escasa significación, unas circunstancias que se explican por la importante alteración de los suelos debido a su escasa profundidad por falta de acumulaciones estratigráficas. Este panorama coincide con el de Arroyo Culebro, donde todo este material apareció en posición secundaria lo que resta mucha información. No obstante, proporciona algunos datos valiosos sobre el horizonte cronocultural del yacimiento y acerca del marco de relaciones. 
5.1) El material cerámico: Ante la imposibilidad de conocer las asociaciones, hemos optado por.considerar todos les restos recuperados, de forma global, y estudiar el conjunto atendiendo al proceso de elaboración: a mano o a torno y por el tipo de acabado y decoración, a sabiendas que cualquiera de los fragmentos realizados a mano podría estar asociado a las producciones de torno y que los vasos de cocciones oxidantes y decoración pintada convivieron con los recipientes de superficies grises y decoraciones estampilladas.

5.1a) La cerámica a mano (Láminas 3 a 6): Representa poco menos del $25 \%$ del total recuperado, aunque su presencia es muy desigual en los distintos puntos del yacimiento, ya que es mayoritaria en la zona sur, mientras que hacia el norte domina claramente la realizada a torno. Se caracteriza por estar realizada en hornos reductores que proporcionan a las pastas unos tonos grises/negros o pardos, a veces con manchas que indican una cierta irregularidad en las condiciones durante del proceso de cocción. Atendiendo a su acabado, estas piezas pueden quedar englobadas en dos grandes bloques: finas y las toscas.

Aunque la presencia de esta cerámica de elaboración manual se podría explicar perfectamente como una producción que acompaña a las series realizadas a torno de la Segunda Edad del Hierro, creemos que la existencia de algunos fragmentos pertenecientes a pequeños vasos de paredes finas y decorados con minuciosas incisiones (Lámina 3, n³6) indicaría que se trata de piezas claramente pertenecientes al Hierro Antiguo, del que también son características las asas de pezón perforado (Lámina 3,5) que en general desaparecen en momentos más avanzados.

Otros rasgos que permiten incluir en el Hierro I, al menos a una parte de este conjunto cerámico, son los perfiles acusados de algunas de las cazuelas de superficies cuidadas (Lámina 3, n⿳8一-15), pues aunque no pueden reconstruirse formas completas, sí es posible comprobar el dominio de las cazuelas de perfil carenado. Así mismo los acabados más cuidados, generalmente espatulados $\mathrm{y}$, excepcionalmente bruñidos, correspondientes a recipientes de tamaños pequeños y medios con paredes relativamente delgadas (Lámina 3), son muy característicos de los horizontes del Hierro Antiguo ya que estos tratamientos se abandonan cuando la vajilla de mesa es sustituida por ejemplares torneados.

Sin embargo, entre estas cerámicas finas, hay ausencias destacables como son las decoraciones pintadas post cocción y los acabados a la almagra, presentes también en la mayoría de los yacimientos del Hierro I de este entorno, a ello se suma que tanto las decoraciones incisas creando diseños geométricos, como los mamelones perforados, son mucho más escasos en la Segunda Edad del Hierro que en la Primera. Otro dato destacable es que la mayoría de los fragmentos con algunos de estos rasgos más arcaizantes (Blasco, C. y otros fig. 10, p. 164), fueron recuperados durante la prospección inicial en una zona muy concreta, al sur del camino que corta el yacimiento, lo que nos invita a pensar que es en esta área donde debía localizarse el asentamiento del Hierro Antiguo, posiblemente sobre una extensión limitada.

Entre las cerámicas de este grupo destaca, además de los cuatro fragmentos con decoración de finas incisiones (Lámina 3, $\mathrm{n}^{\circ} 3-6$ ), un pequeño recipiente ornamentado con 

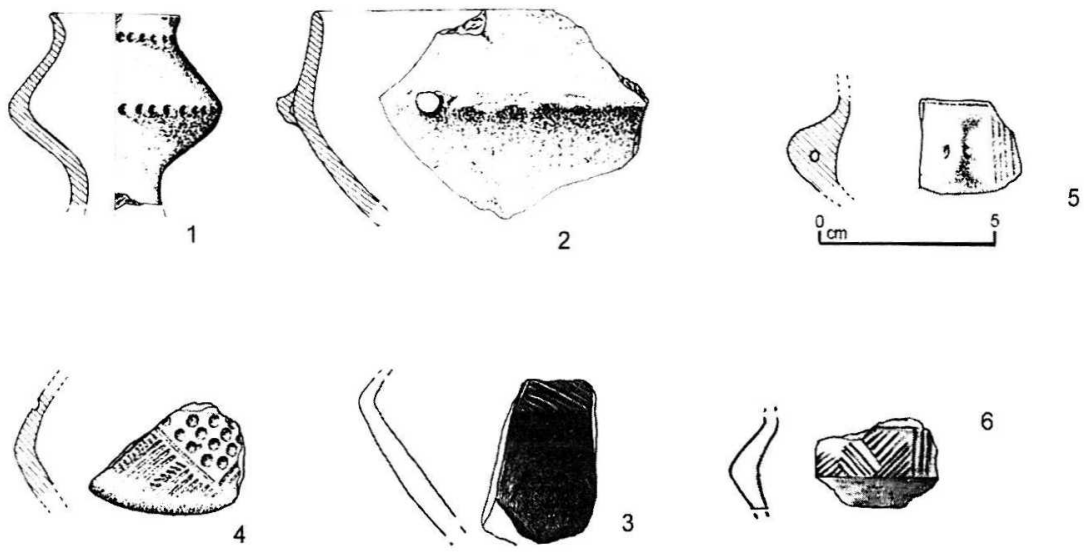

6

0 5
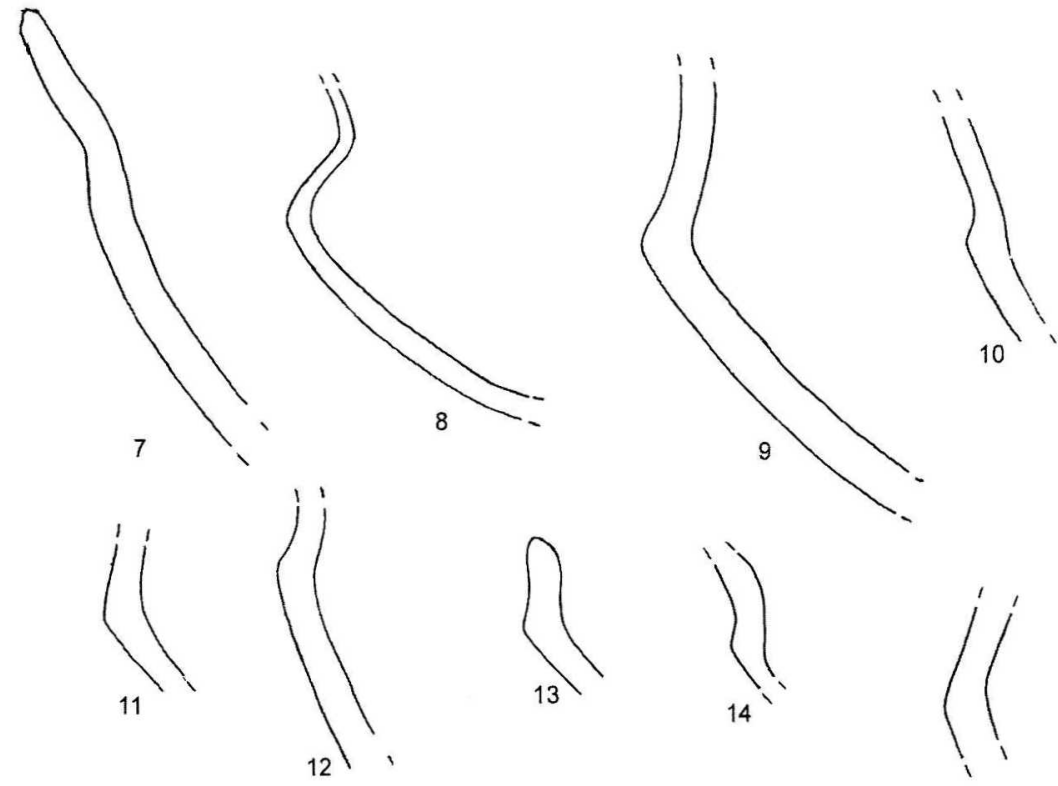

0

$\llcorner\mathrm{cm}$ 5

15

Lámina 3: Cerámicas finas realizadas a mano procedentes del yacimiento Arroyo Culebro. 1: kotiliskos decorado con impresiones de hoyitos. 2: Fragmento de cuemco con pequeno mamelón perforado. 3 a 6: Fragmentos cerámicos con decoración incisa. 7 a 15: Perfiles de vasos carenados. 


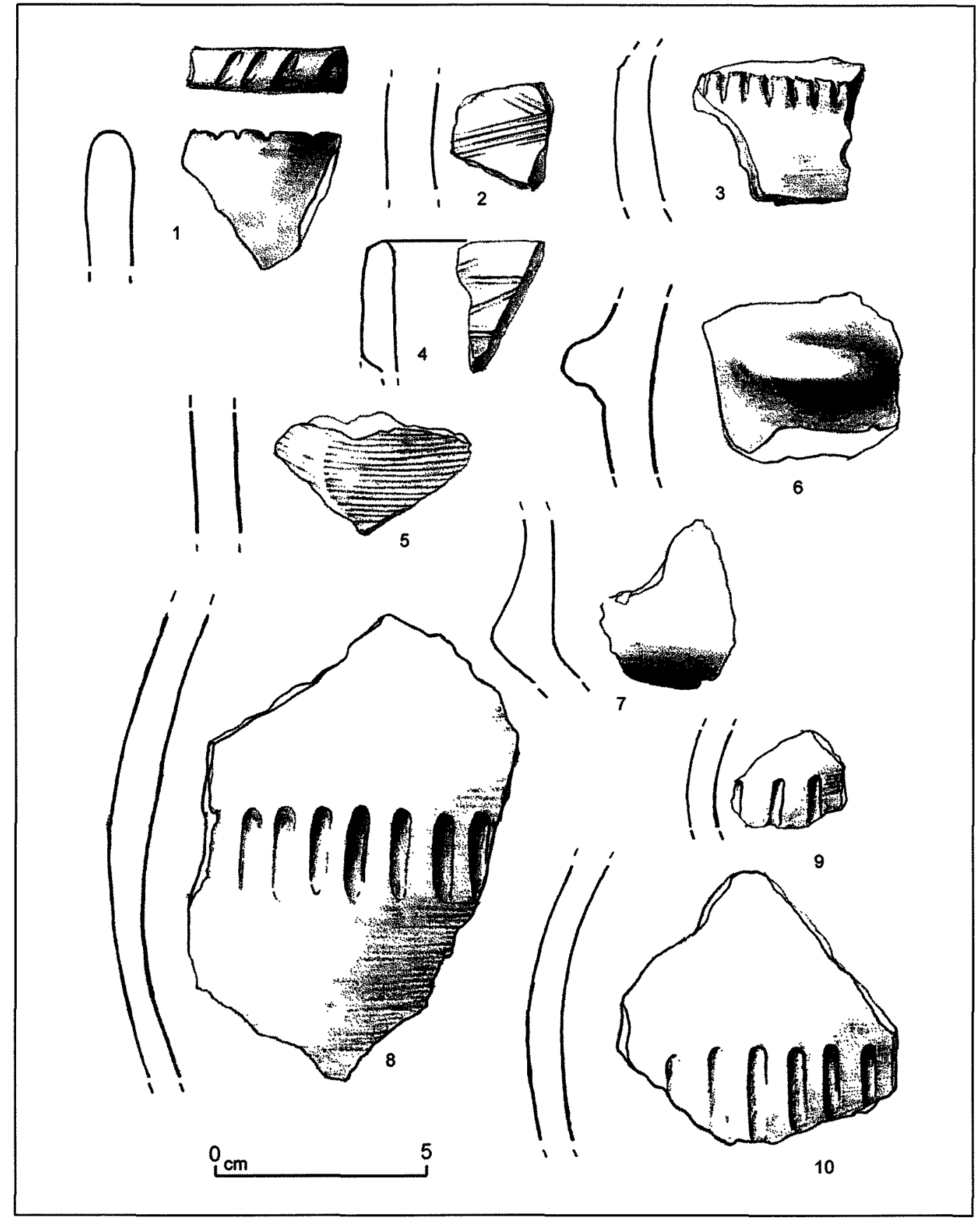

Lamina 4: Cerámicas toscas realizadas a mano procedentes del yacimiento Arroyo Culebro. 1: Fragmento de boca con decoración de impresiones. 2, 4 y 5: Fragmentos de galbos con acabado a cepillo. 3 y 8 a 10: Galbos con ornamentación incisa. 6 y 7: Decoración de mamelones. 

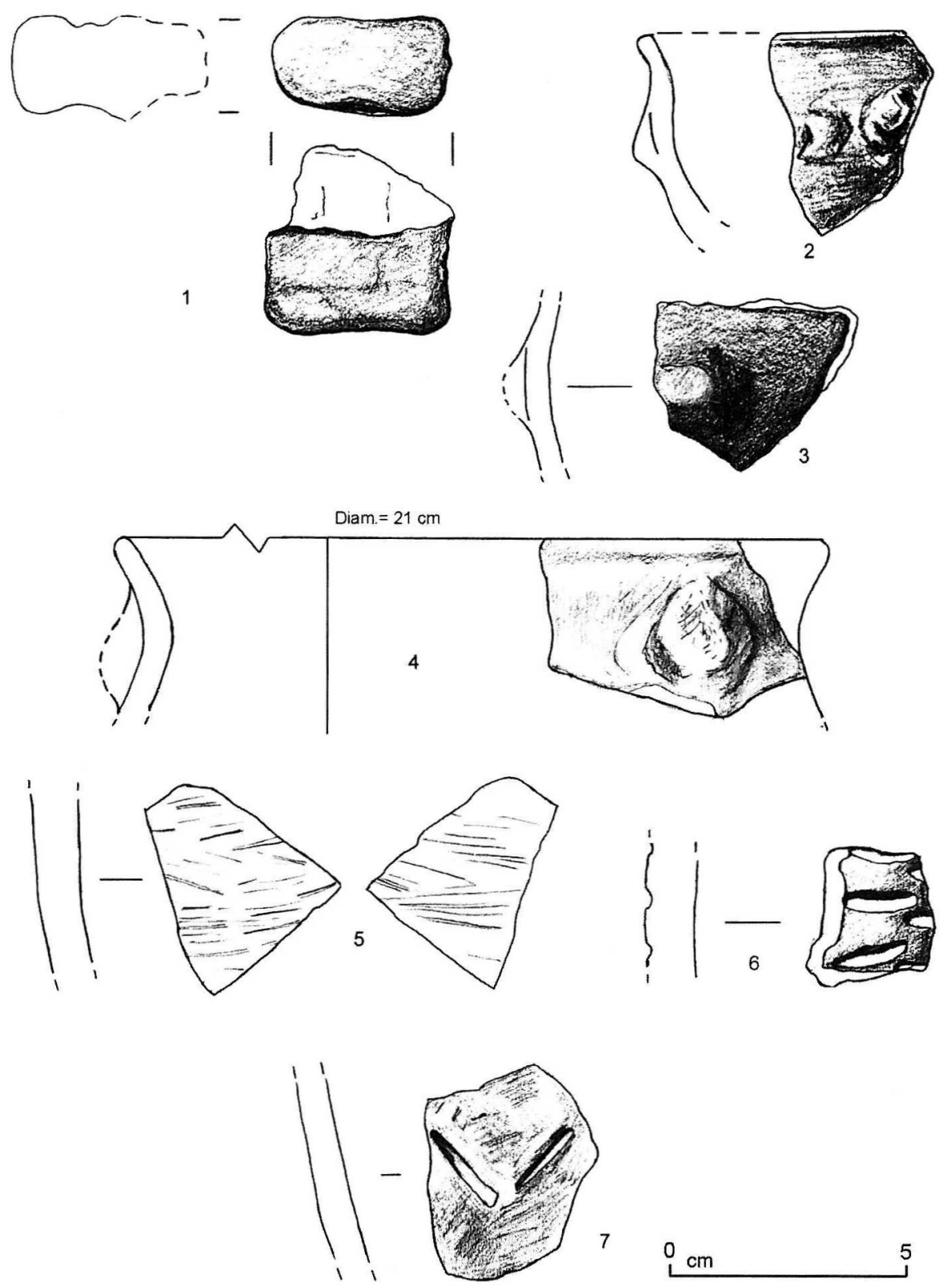

Lámina 5: Cerámicas toscas realizadas a mano procedentes del yacimiento Arroyo Culebro.

1 a 4: Mamelones plásticos. 5: Acabado a cepillo. 6: Incisiones realizaas con instrumento grueso. 


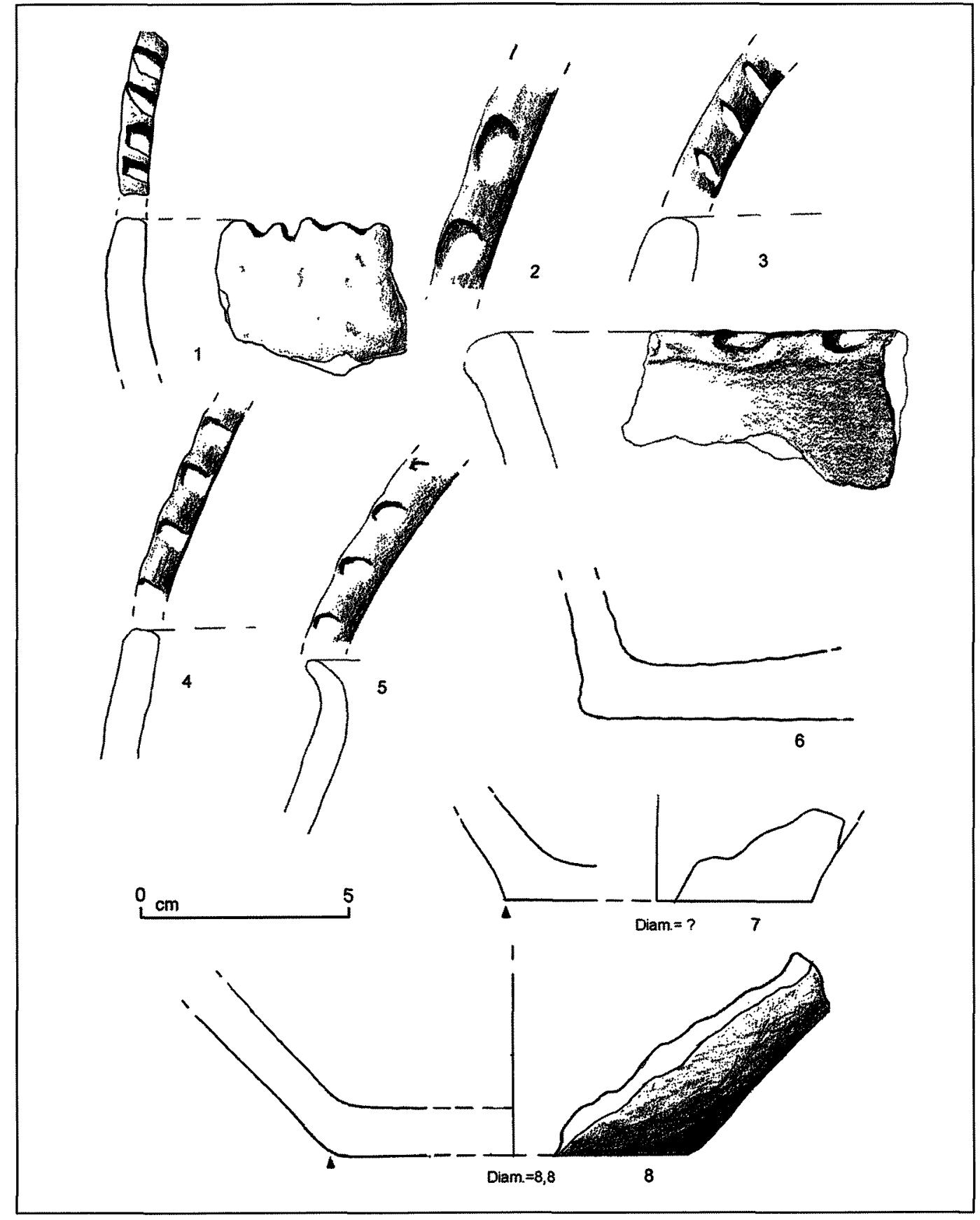

Lamina 6: Cerámicas toscas realizadas a mano procedentes del yacimiento Arroyo Culebro.

1 a 5: Fragmentos de bocas con decoración de digitaciones. 6 a 8: Bases planas, 6 y 7 con talón marcado. 
decoración de hoyitos en la línea de carena que presenta la base abierta (Lámina 3,1). Se trata de un kotiliskos, posiblemente perteneciente a un kernos, sobre cuya boca o parte alta de las paredes estaría situado. Estos recipientes de libaciones, conocidos y muy frecuentes en el Mediterráneo Oriental, de donde son originarios, se encuentran en numerosos yacimientos de la Prehistoria Reciente europea, tanto continental como mediterránea, a partir del Bronce Final generalizándose en el Hierro Antiguo, momento del que conocemos algunos ejemplares en la Península Ibérica, particularmente en el Valle del Ebro: Cabezo de Monleón, Cortes de Navarra (Beltrán, A., 1962) y Cueva de Olvena (Rodanés, J. Ma y Ramón, N., 1996: 100 y fig.47, 1). El hecho de que estos tres ejemplares de la I Edad del Hierro, se encuentren en el Valle del Ebro, podría ser indicio de la existencia de relaciones entre las cuencas del Tajo y Ebro, posiblemente a través del corredor Henares-Jalón, unos contactos que, por supuesto, no son los únicos pero explican "el aire de familia" de muchos de los elementos y rasgos de las producciones vasculares de la I Edad del Hierro entre ambas zonas.

En consonancia con las características de las cerámicas finas se encuentran algunos de los rasgos de las series de superficies menos cuidadas, es el caso de los tratamientos de cepillados parciales (Láminas $4, \mathrm{n}^{\circ} 2,4$ y 5 ; y Lámina $5, \mathrm{n}^{\circ}$ ) ya que se trata de un acabado muy usual en prácticamente todos los círculos del Hierro Antiguo peninsular y, concretamente en esta región del Tajo. Se trata de otro de los rasgos que confirma la existencia de esos contactos a los que acabamos de referirnos y que afectan a otros aspectos técnicos, morfológicos y ornamentales de este grupo de cerámicas, entre los que cabe destacar la reiteración de bordes decorados con digitaciones (Lámina $6 \mathrm{n}^{\circ} 1,2,4$ y 5) y ungulaciones (láminas. $4, \mathrm{n}^{\circ} 1$ y $6, \mathrm{n}^{\circ} 3$ ), las incisiones en cuellos y cuerpo (Lámina $4, \mathrm{n}^{\circ} 3,8,9$ y 10) y las aplicaciones plásticas en forma de mamelones (Lámina $4, n^{\circ} 6$ y Lámina $5 n^{\circ} 1-4$ ); entre los aspectos formales destacamos los pies planos con o sin talón indicado (Lámina 6) y los labios redondeados o apuntados y los perfiles sencillos (lámina $4, \mathrm{n}^{\circ} 1$ y 4 y Lámina $6, \mathrm{n}^{\circ} 1$ a 5$)$.

Sin embargo, salvo los acabados a cepillo que se abandonan pronto, el resto de las características ornamentales y morfológicas se mantienen en las producciones a mano de la Segunda Edad del Hierro, por lo que algunas de estas piezas podrían acompañar a las producciones torneadas, pues a lo largo de buena parte de la Edad del Hierro muchos de los recipientes de cocina y almacenaje siguen realizándose a mano y reproduciendo modelos tradicionales, aunque presemtes en proporciones relativamente bajas que disminuyen a medida que avanza el tiempo.

5.1b) La cerámica torneada (Láminas 7-15): Su aparición en esta zona se vincula al inicio de la Segunda Edad del Hierro coincidiendo con la iberización del interior peninsular, a partir del s. V a. C., esto explica que en la totalidad de los yacimientos conocidos del entorno geográfico de la cuenca media/alta del Tajo estén presentes las producciones de "tipo ibérico", con pastas rojizas y decoración pintada, una variedad que, en la totalidad de los conjuntos conocidos de este círculo cronocultural, convive con ejemplares torneados de superficies oscuras, grises o negras, que recuerdan las calidades de las producciones realizadas a mano, más cuidadas, los cuales comparecen siempre en proporciones pequeñas. 
La cerámica de "tipo ibérico" y la cerámica “carpetana” (Láminas 7-15): Es, con diferencia, el conjunto cerámico más numeroso ya que supone algo más del $60 \%$ del total de los restos recuperados, una proporción que resulta normal, incluso en niveles relativamente tempranos de la Segunda Edad del Hierro pues la sustitución de la elaboración manual por la torneada debió de producirse en un lapso temporal relativamente corto, en la primera mitad del siglo $\mathrm{V}$ a. C., y a partir de mediados de esta centuria, las producciones manuales se mantienen en proporción descendente, siempre por debajo del $30 \%$.

El conjunto de cerámicas "de tipo ibérico" y "carpetanas" presentes en el yacimiento de Arroyo Culebro son una muestra muy representativa de los horizontes antiguos del Hierro II en la zona; está caracterizado por la coexistencia de ejemplares típicamente ibéricos, pintados con diseños simples o lisos y piezas específicas del área carpetana, singularizadas por presentar la superficie, total o parcialmente, cubierta por una aguada más o menos espesa de pintura irregular en la que los distintos brochazos dejan huellas de pintura de diferente intensidad.

Esta cerámica "a brochazos" o "de imitación de madera" fue identificada hace ya tiempo como específica del área carpetana (Cuadrado, E., 1973) y denominada "cerámica jaspeada" o de "imitación de madera" En el yacimiento que nos ocupa representa casi la mitad de la cerámica pintada (o lo que es lo mismo, en torno al $30 \%$ del total de los restos vasculares) y puede presentarse exclusivamente como una aguada (Lámina 7 y Lámina $8, \mathrm{n}^{\circ} 2$ y 4) o sirviendo de base a la decoración pintada de tipo ibérico (Lámina $8, \mathrm{n}^{\circ} 1$ y 3 y Lámina 9). El color de las aguadas varía, como en el caso de la pintura ibérica, desde el rojo relativamente claro, hasta el negro manganeso.

Poco se ha insistido en esta variante de cerámica pintada, muy característica de este entorno de la cuenca del Tajo y, que en proporciones muy bajas traspasa el ámbito de lo que será el mundo carpetano. Sólo en algunos yacimientos más meridionales, pertenecientes al círculo oretano de la cuenca del Guadiana está bien representada, caso de Oreto (Nieto G y otros, 1980), aunque puntualmente la encontramos también en el Valle del Duero, concretamente en el yacimiento vallisoletano de El Soto de Medinilla (Escudero, Z., 1995, fig. 8,2). Su límite hacia el Este parece coincidir con el del ámbito carpetano ya que tenemos noticias de su presencia en algunos yacimientos alcarreños de la cuenca media del Henares, concretamente en el yacimiento de "los Morales" (vid. Lámina 20, término de Jadraque (Valiente, J., 1995: 48), pero no consta su presencia en yacimientos más septentrionales y orientales, pertenecientes al mundo celtibérico.

Por otra parte, aunque no se hace referencia expresa a su presencia en yacimientos conquenses, es posible que algunos de los ejemplares que se describen "con restos de pintura" o "engobados" procedentes de distintas necrópolis, como Las Madrigueras, Buenache de Alarcón u Olmedilla de Alarcón (Mena, P., 1985), podrían presentar este peculiar engobe jaspeado. En áreas más netamente ibéricas no hay, de momento, noticias de este tipo de tratamiento, como es el caso de las necrópolis albacetenses. Dentro del área de dispersión, la frecuencia de este engobe resulta mucho más intensa en los yacimientos del corazón de la Carpetania: la cuenca del Tajo a su paso por las provincias de Madrid y el oriente de la de Toledo, mientras que en la periferia se presenta de manera más esporádica, lo que lo define como uno de los rasgos más significativos de este ámbito. 


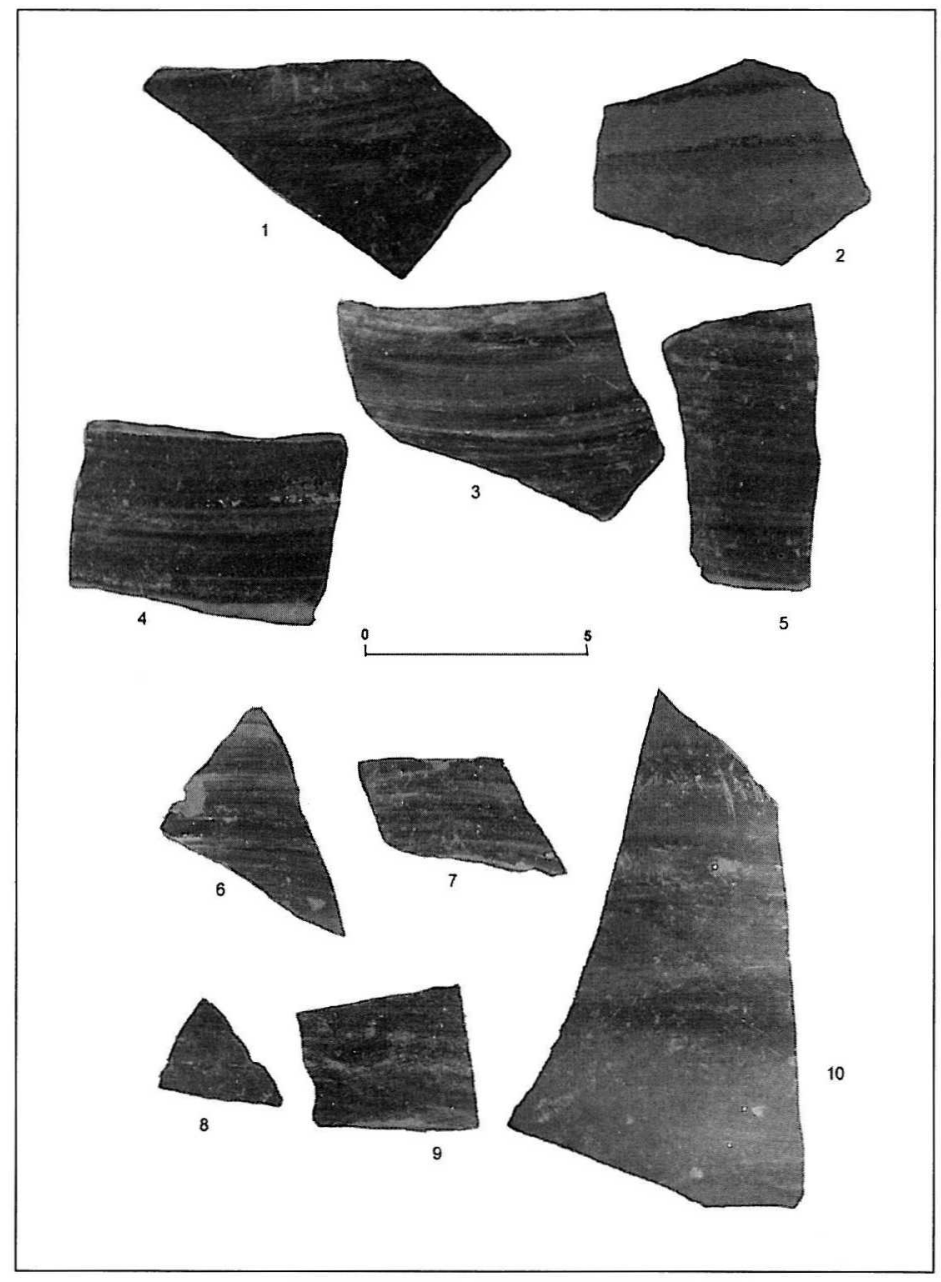

Lámina 7: Fragmentos cerámicos realizados a torno con pintura "jaspeada" procedentes del yacimiento Arroyo Culebro.

Difícil se presenta, de momento, la búsqueda del origen de este irregular engobado, aunque no descartamos la posibilidad de que se trate de un intento de seguir la tradición de las almagras o las pinturas postcocción que cubren parte o toda la superficie de las producciones de mano y que fueron relativamente abundantes en momentos avanzados del Hierro antiguo en la misma zona de su dispersión, anteriores a la irrupción del torno y, por tanto, antecesoras inmediatas de los jaspeados. Tampoco puede desestimarse la posibilidad de emulación de los barnices rojos de los talleres alfareros del mundo colonial y de sus imitadores, o quizás haya que pensar que "es un síntoma de inmadurez característico de un torno inicial" como pensó F. Watenberg del espatulado que presentan algunos ejemplares del Valle del Duero (Gómez, A. y Sanz, C., 1993: 354), hipótesis esta última, menos 


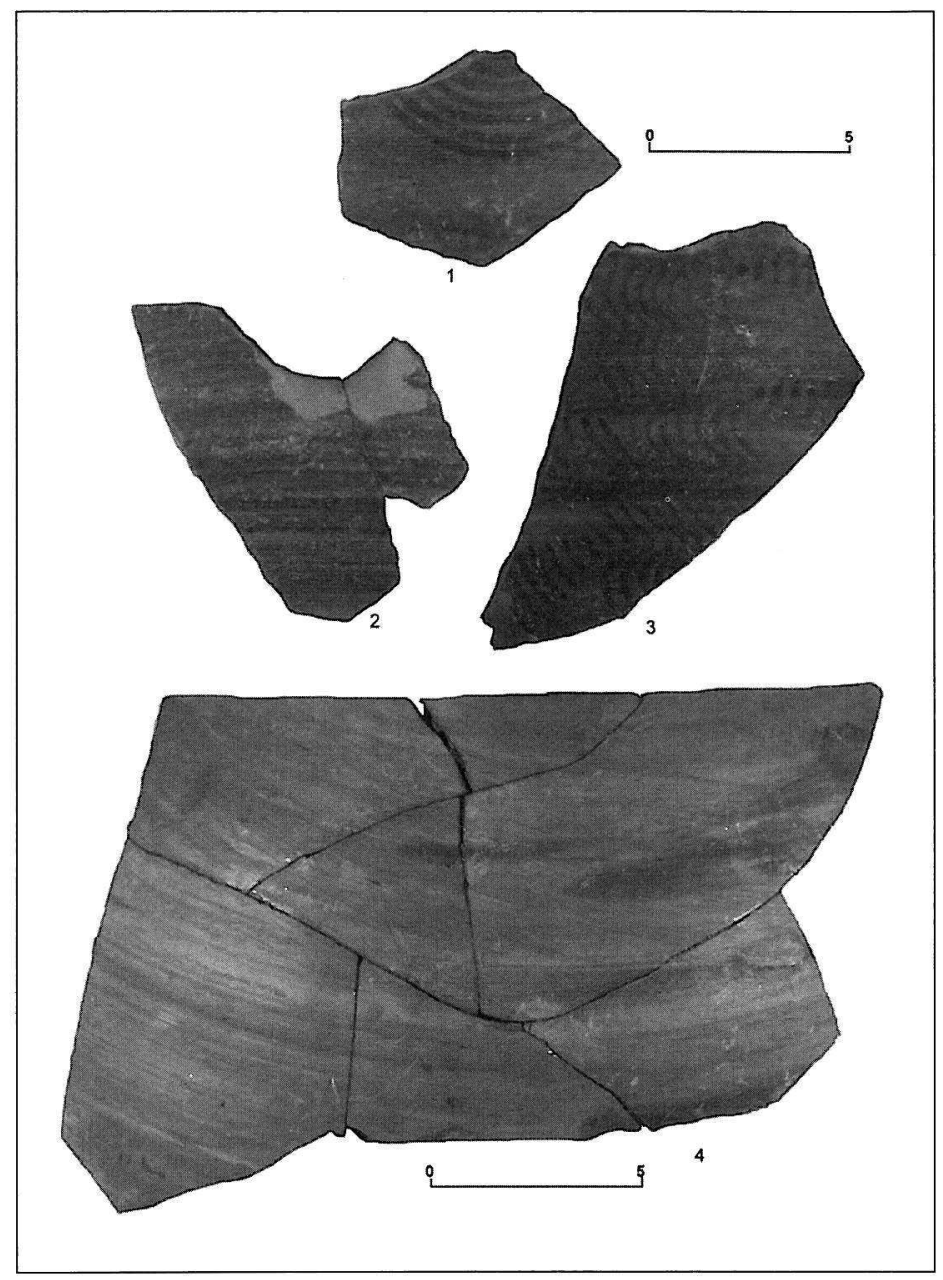

Lámina 8: Fragmentos cerámicos realizados a torno con pintura "jaspeada" procedentes del yacimiento Arroyo Culebro; los fragmentos 1 y 3 tienen además del "jaspeado" decoración de diseños geométricos realizados con pintura más uniforme.

probable ya que se trata de un fenómeno que persiste en lugares como el Cerrón de Illescas desde el s. IV hasta el siglo II a.C. (Valiente, S. 1995: 81-86). Desgraciadamente la falta de excavaciones sistemáticas y de estudios específicos sobre cerámica carpetana no nos permite conocer bien la evolución de este singular acabado a brochazos, si bien parece que su popularidad es mayor en los momento de la introducción del torno. Lo cierto es que en los ejemplares torneados más antiguos de la zona es extraordinariamente popular aplicándose, aun a fuerza de enmascarar los diseños pintados, como lo evidencian los materiales de Arroyo Culebro pues la aplicación de las aguadas no se limita a vasos sin decoración, sino que se incorpora a piezas que posteriormente se ornamentan con diseños realizados con una pintura más espesa y regular (Lámina $8, n^{\circ} 1$ y 3 y Lámina 9, $n^{\circ} 1,2$ y 4). 


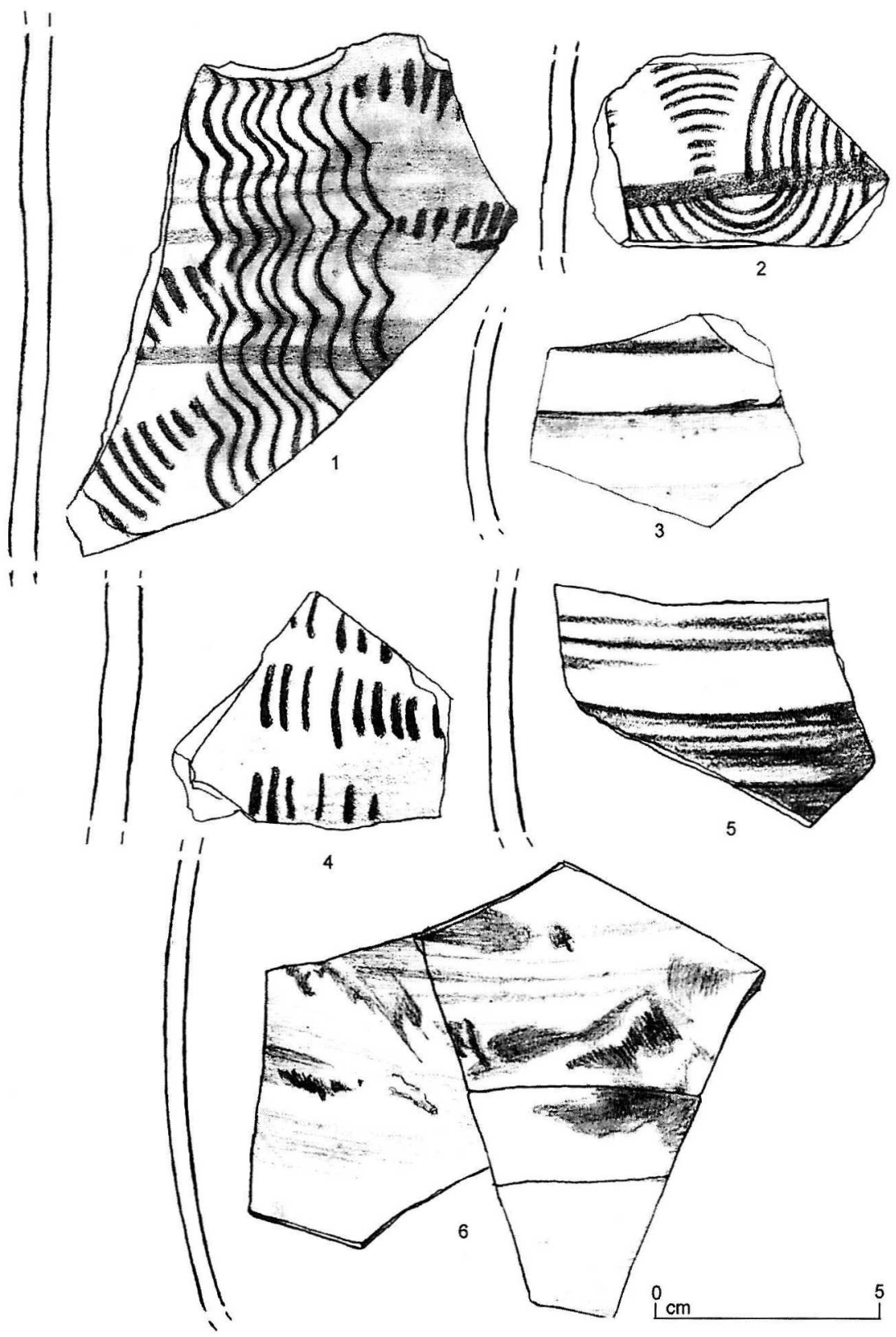

Lámina 9: Fragmentos cerámicos realizados a torno "jaspeados" y/o con diseños pintados procedentes del yacimiento Arroyo Culebro. 

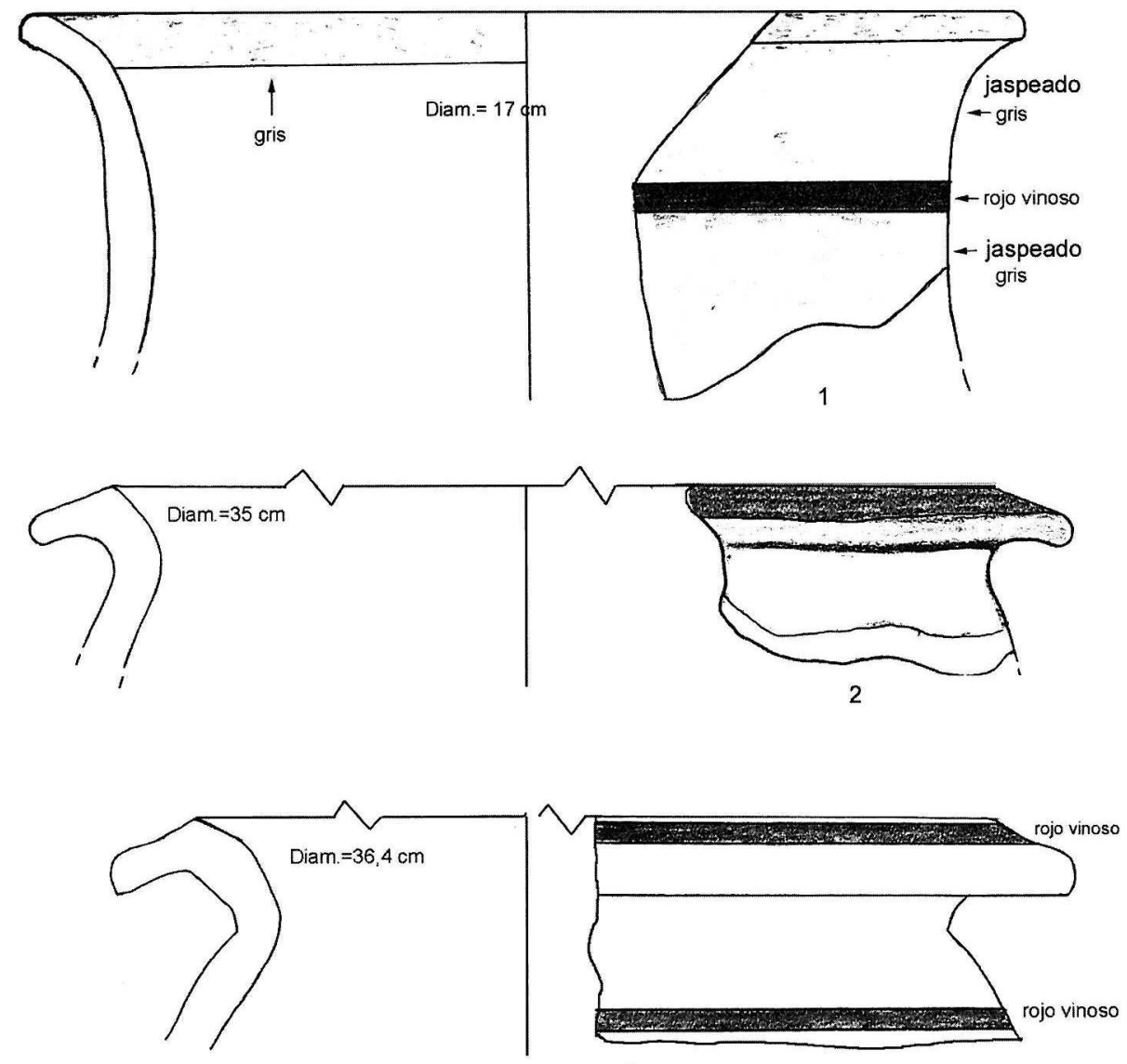

3

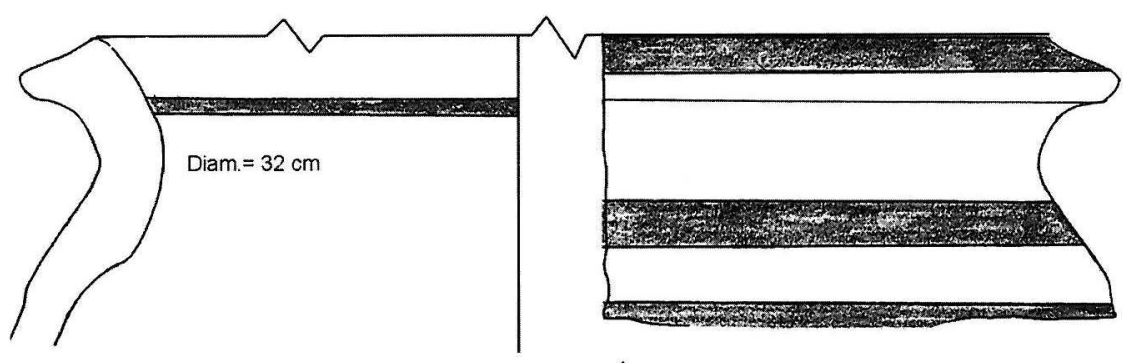

4

0
$\mathrm{~cm}$

Lámina 10: Fragmentos de boca pertenecientes a grandes recipientes cerámicos realizados a torno y decorados con bandas horizontales pintadas, procedentes del yacimiento Arroyo Culebro. 


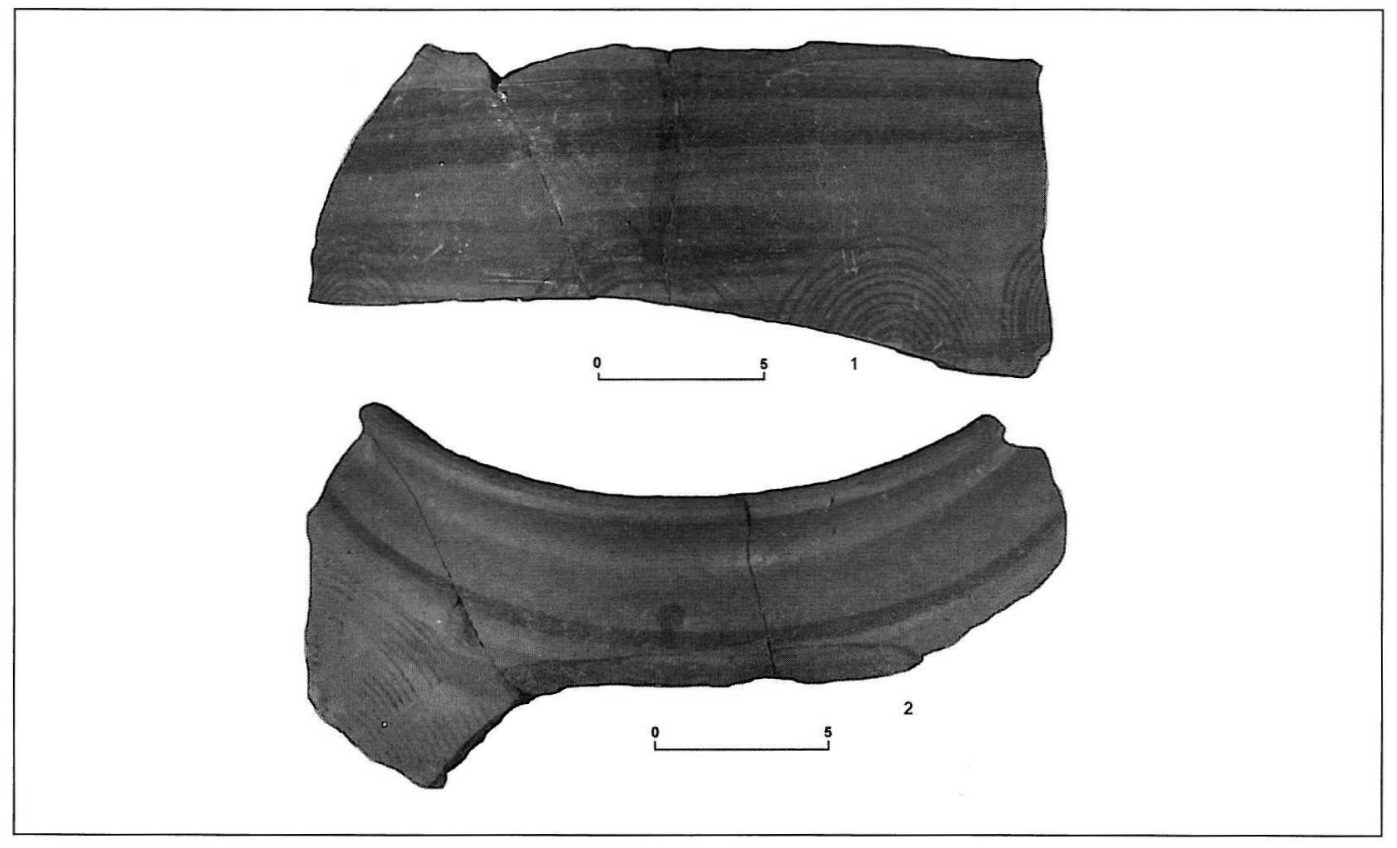

Lámina 11: Fragmentos pertenecientes a grandes recipientes cerámicos realizados a torno y decorados con pintura, procedentes del yacimiento Arroyo Culebro. 1: Jaspeado y pintado. 2: Fragmento de boca con decoración geométrica pintada.

Las cerámicas de tipo ibérico (Láminas 9 a 15), cuando están decoradas, presentan diseños muy simples entre los que dominan las bandas horizontales de distintas anchuras, solas (Láminas 10 y 13) o combinadas con otros motivos (Láminas 11 y 12). Son también frecuentes los círculos y semicírculos concéntricos, a veces, creando guirnaldas (Láminas 11 y 12,), los segmentos de círculo (Lámina 9, no 4) o las "melenas" (Lámina 9 n 1), todos ellos interpretados con trazos caligráficos, hechos con pinceles muy finos y múltiples y con compás. La combinación de bandas más o menos anchas y diseños concéntricos de trazado caligráfico es frecuente en los niveles del ibérico pleno más antiguo que abarca desde mediados del s. V a inicios del III (Mata, C., 1991: 122), una cronología que puede perfectamente aceptarse para este yacimiento.

Otro dato que podría reforzar esta datación es la existencia de algunos fragmentos con pintura blanca (Lámina $13, \mathrm{n}^{\circ} 6$ ), concretamente utilizada como fondo de bandas realizadas en marrón rojizo, una combinación que encontramos en yacimientos como Los Villares de Caudete (Mata, C., 1991: 137), con el que guarda paralelos, especialmente con el nivel IV.

Poco podemos decir de las formas ya que no hay ningún ejemplar completo, pero existen caliciformes (lámina 14, $\mathrm{n}^{\circ} 6$ y 7), platos, un único tonelete (Lámina 15) y, sobre todo, tinajillas y tinajas (Lámina 10), tanto de perfil con tendencia globular (Lámina 113, $\mathrm{n}^{\circ}$ 


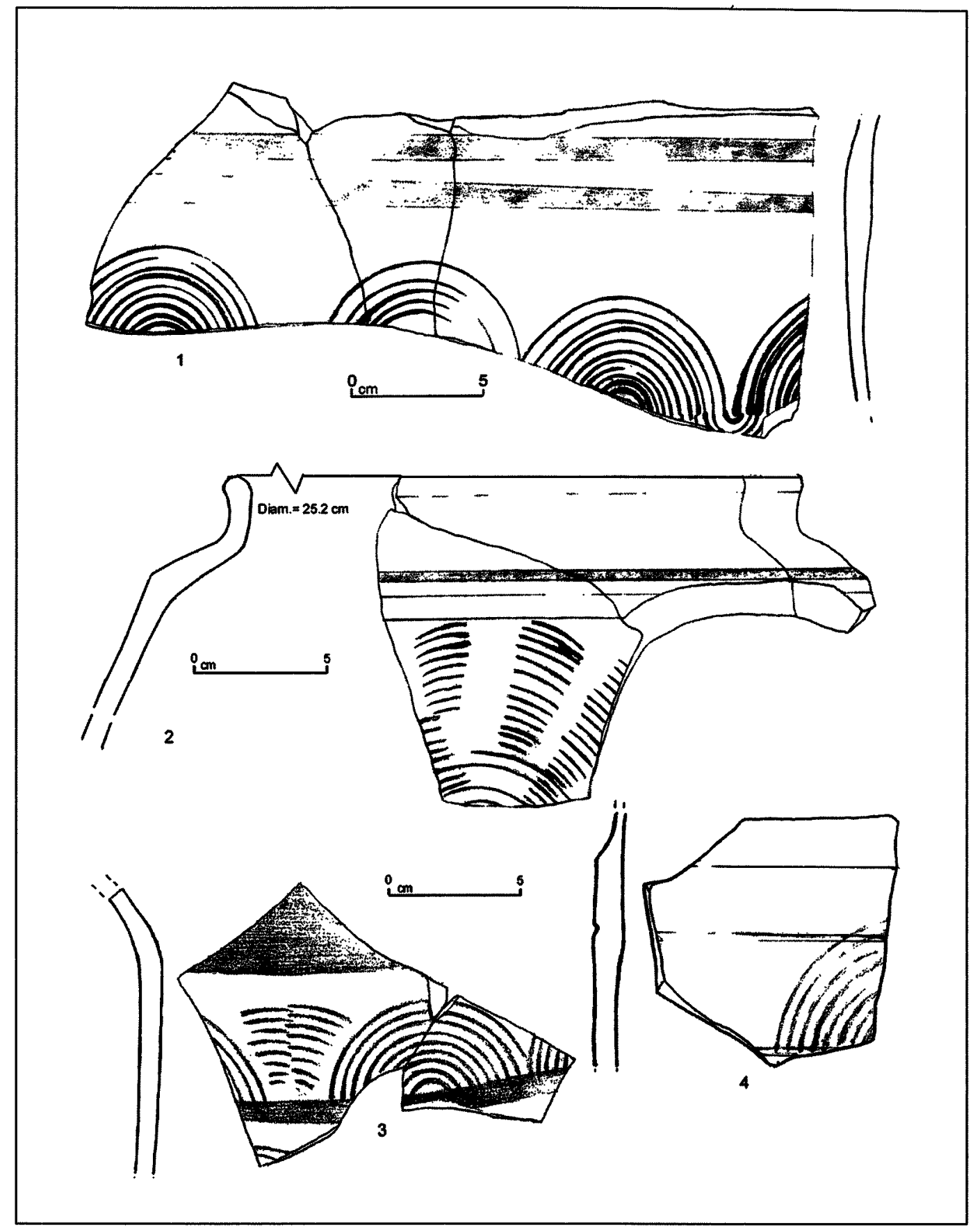

Lamina 12: Fragmentos pertenecientes a grandes recipientes cerámicos realizados a torno y decorados con motivos geométricos "a compás” pintados, procedentes del yacimiento Arroyo Culebro. 

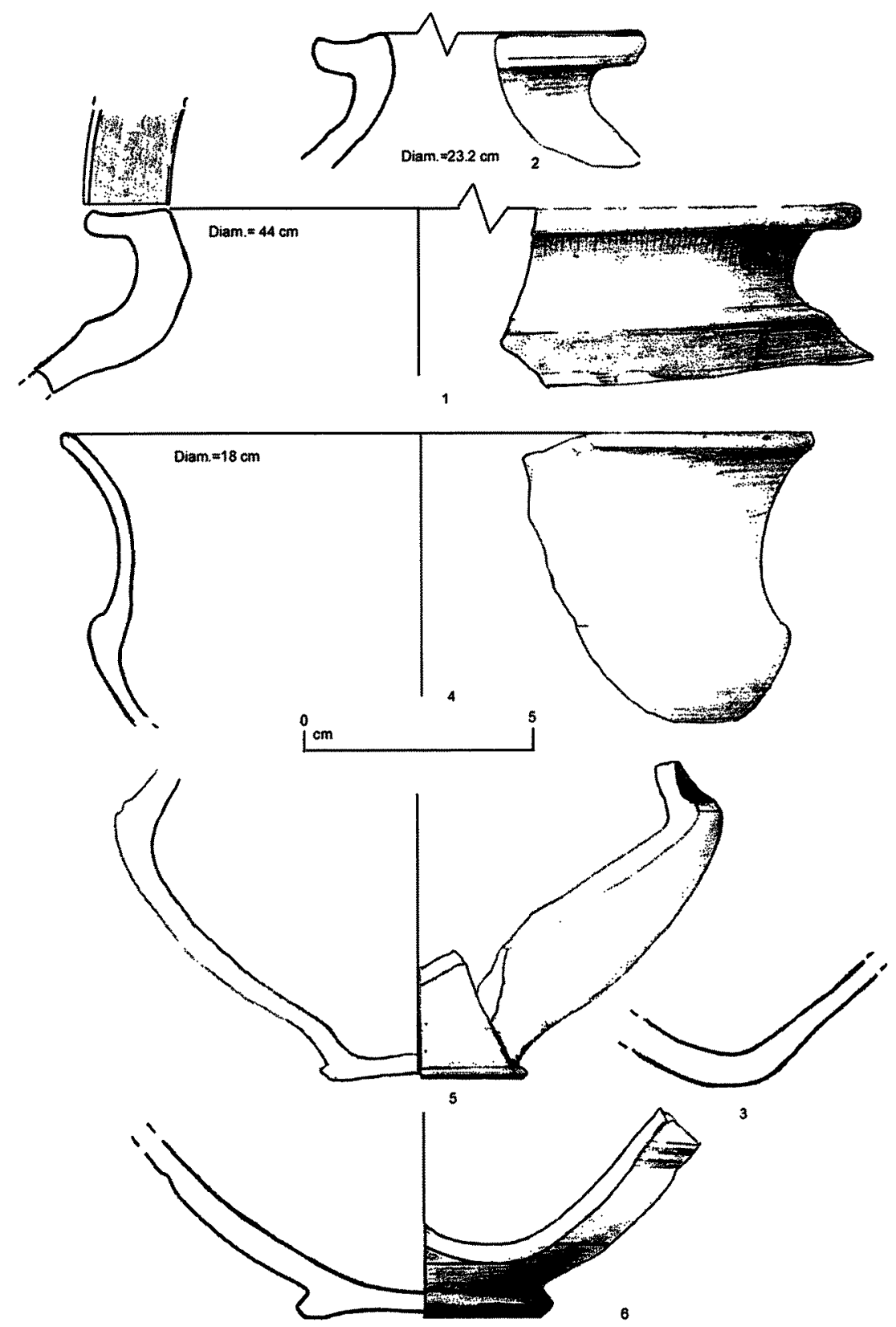

Lámina 13: Fragmentos pertenecientes a bocas de recipientes cerámicos realizados a torno, algunos de ellos decorados con bandas pintadas, procedentes del yacimiento Arroyo Culebro. 3 a 7: Diferentes tipos de bases. 

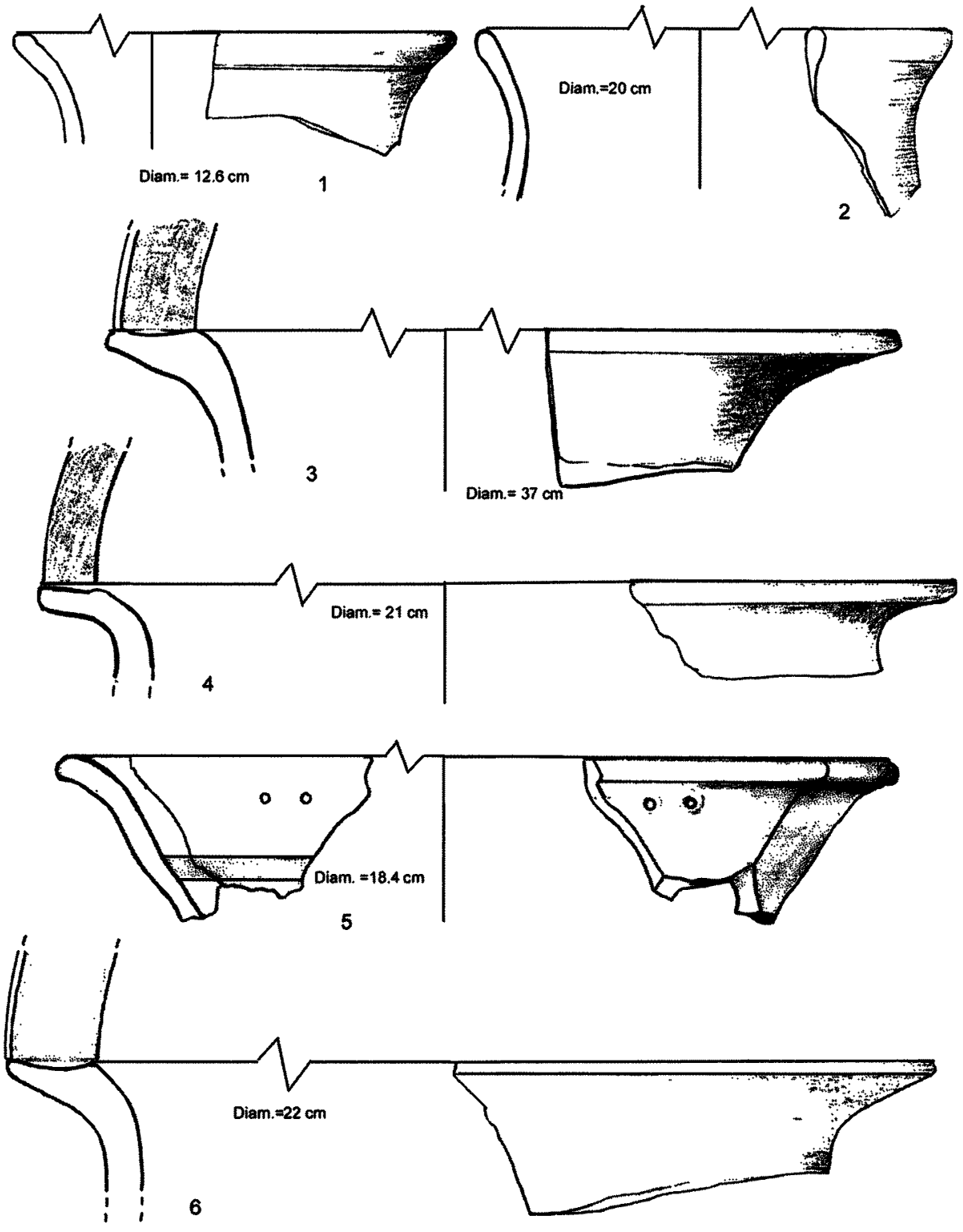

5
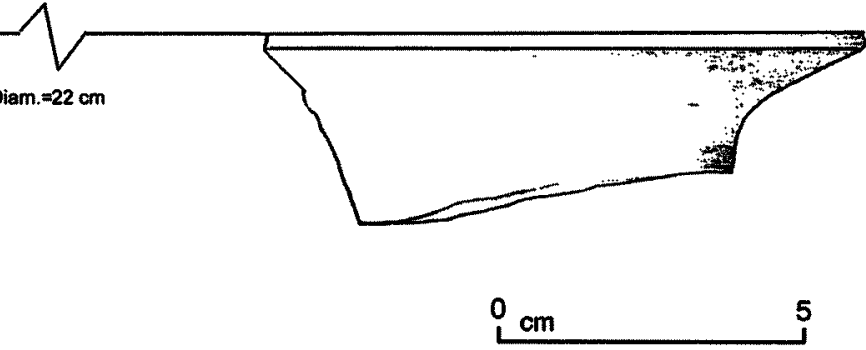

Ldmina 14: Fragmentos pertenecientes a bocas de cuencos y platos cerámicos realizados a torno, algunos de ellos decorados con bandas pintadas, procedentes del yacimiento Arroyo Culebro. 

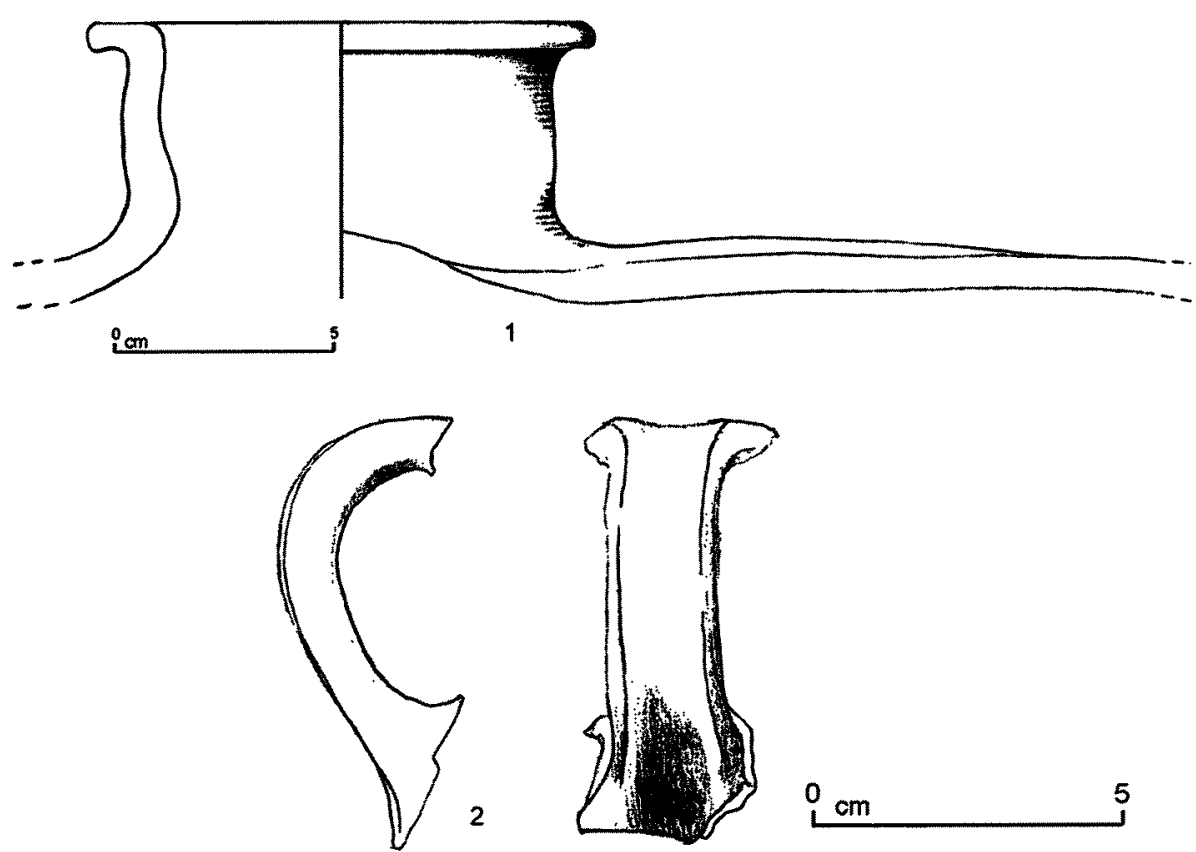

$\stackrel{0}{\mathrm{~cm}}$

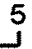

Lamina 15: Fragmento de tonelete y asa cinta realizados a torno, procedentes del yacimiento Arroyo Culebro.

1 y 2), como quebrada (Lámina $13, \mathrm{n}^{\circ} 2$ ), una categoría formal frecuente en los yacimientos ibéricos y que en este caso permite explicar el por qué de la desaparición de los silos, tan numerosos en yacimientos de la Edad del Bronce, pero que a partir de la Edad del Hierro son sustituidos por otros sistemas de almacenaje, fundamentalmente, por estos grandes contenedores cerámicos; ello determina un cambio importante en la fisonomía de los restos inmuebles de los yacimientos que pasan de grandes campos de silos, destinados muchos de ellos al almacenaje de excedentes, a presentar únicamente simples "manchas oscuras" que coinciden con los débiles suelos de cabañas exentas de planta irregular

Las morfologías de este lote vascular resulta poco variada y de perfiles simples, más propias en el ámbito ibérico de lo que se ha dado en llamar el "ibérico antiguo", si bien la presencia excepcional de formas más complejas y específicas como el tonelete advierte de que la etapa más antigua de la iberización de esta área responde a un momento de plenitud de la cultura ibérica, a partir de mediados del s. V a. C.

La cerámica gris/negra a torno (Láminas 16 y 17): Esta variedad no alcanza el $10 \%$ de la muestra recuperada en el yacimiento, porcentaje que resulta habitual en la mayoría de los repertorios vasculares de los yacimientos del Hierro II en la zona. En cuan- 
to a sus acabados, es heredera de la cerámica fina a mano de momentos previos, tanto por la tonalidad negra o gris de sus pastas y superficies, como por el espatulado más o menos intenso de la superficie externa.

También algunos perfiles, con una insinuada línea de carena, recuerdan a los últimos vasos manuales. En general, responden a una tipología muy reducida, en la que son especialmente frecuentes las copas acampanadas (Lámina $16, \mathrm{n}^{\circ} 1$ y 2 y Lámina $17, \mathrm{n}^{\circ} 4$ ), aunque no faltan los cuencos hemiesféricos (Lámina 17, $\mathrm{n}^{\circ} 3$ ) o las tinajillas de labio moldurado que imitan producciones de pasta rojiza, de tipo ibérico (Lámina 17, n²).

Todos los fragmentos cerámicos ornamentados de este tipo de vasos, recuperados en Arroyo Culebro, presentan estampillas asociadas a líneas incisas que delimitan los frisos es, sin duda, la técnica más empleada en esta variante cerámica del ámbito carpetano, cuya temática, siempre geométrica, reproduce una limitada gama de diseños: "SS", aspas, anillos realizados con pequeños trazos, etc., elementos bastante habituales en la alfarería del Valle del Duero y que difiere de las estampillas impresas sobre cerámicas de tipo ibérico, habituales entre algunos círculos del ámbito ibérico, como oretanos, donde encontramos diseños más propios de la plástica mediterránea, como son ovas, flores de loto, etc... Aunque en el yacimiento que nos ocupa no hay ningún ejemplar de "tipo ibérico".con estampillas, éstas no son raras en contextos de cronología y ambiente similar, como la tapa de urna de orejetas de Los Morales de Jadraque, un claro ejemplo de mestizaje (véase Lámina 20, $\mathrm{n}^{\circ}$ 2).

A diferencia de la cerámica a torno de tipo ibérico que está destinada, tanto a servicios de mesa, como a envases de almacenamiento y transporte, esta variedad de tonos oscuros se emplea sólo para recipientes de tamaño pequeño o medio, pero no para grandes contenedores.

5.2) Industria lítica: Como es habitual en este horizonte, los hallazgos de indusria lítica, aunque no son abundantes, sí están presentes en pequeñas proporciones, sin embargo la falta de atención a esta parcela industrial, hace difícil su comparación al no existir apenas bibliografía. La nómina de restos se reduce a un total de 25 unidades pertenecientes a los siguientes objetos: 6 dientes de hoz; 1 raedera/raspador; 1 fragmento de colgante/brazalete; 6 lascas; 2 núcleos; 7 restos de talla/fragmentos de silex; 1 canto de cuarzo/cuarcita y 1 fragmento de cuarcita.

El material lítico tallado se caracteriza por el práctico abandono de las técnicas de trabajo preservadas aún durante horizontes anteriores (tales como la laminación) que implicaban un dominio de la técnica leptolítica y una exigente selección de las variedades líticas. El grueso de la producción se orienta ahora hacia la obtención de lascas, con sistemas siempre altamente expeditivos y ausencia de programación específica.

La captación es extraordinariamente simple. El aprovechamiento de ópalos, materiales de abundante presencia en el contexto litológico inmediato, es una constante. Estas variedades presentan una escasa aptitud técnica, en este caso suficiente dada la limitada exigencia de los sistemas de producción. 

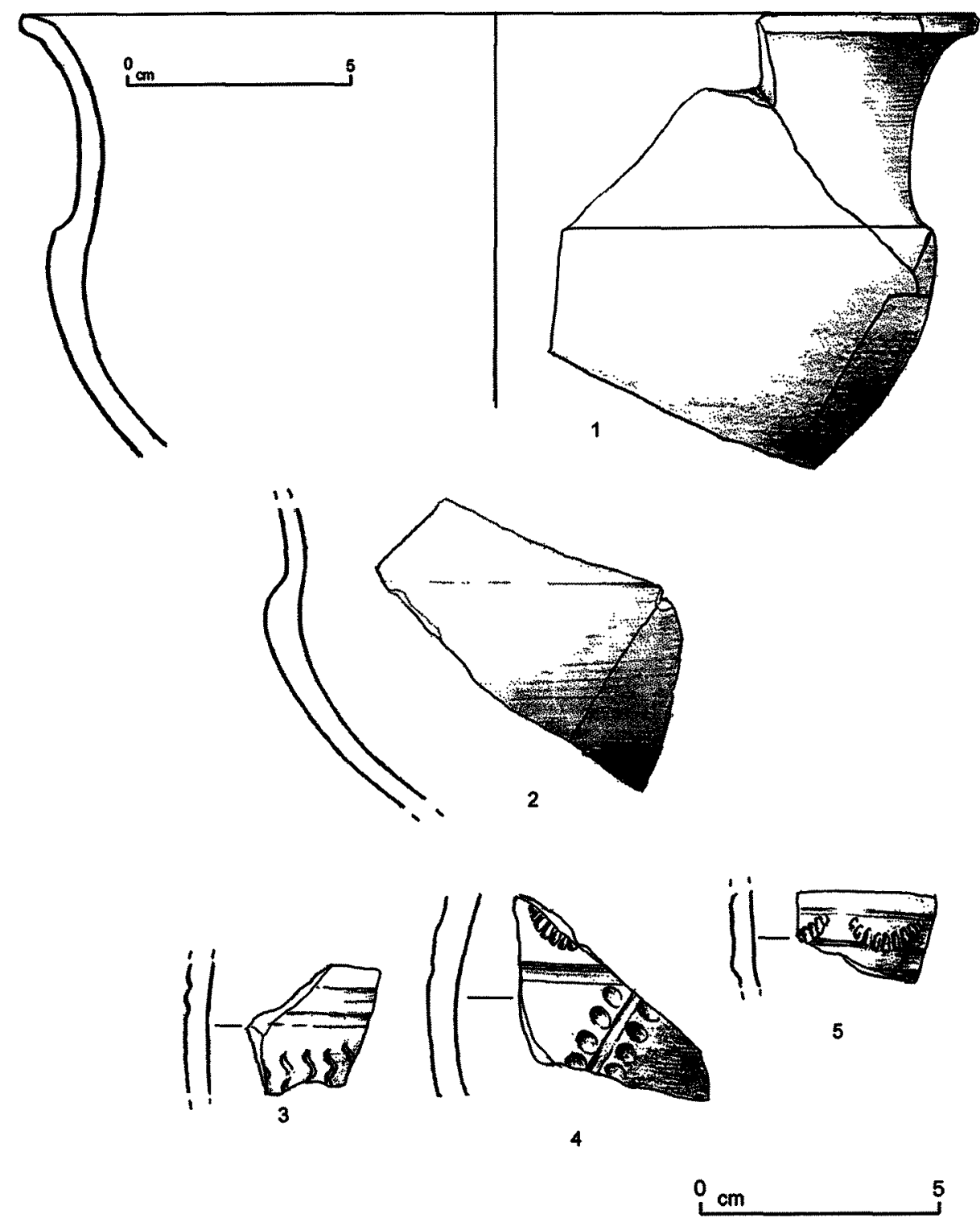

Lamina 16: Fragmentos cerámicos de color gris realizados a torno procedentes del yacimiento Arroyo Culebro. 3 a 6: Decoraciones de estampillas. 

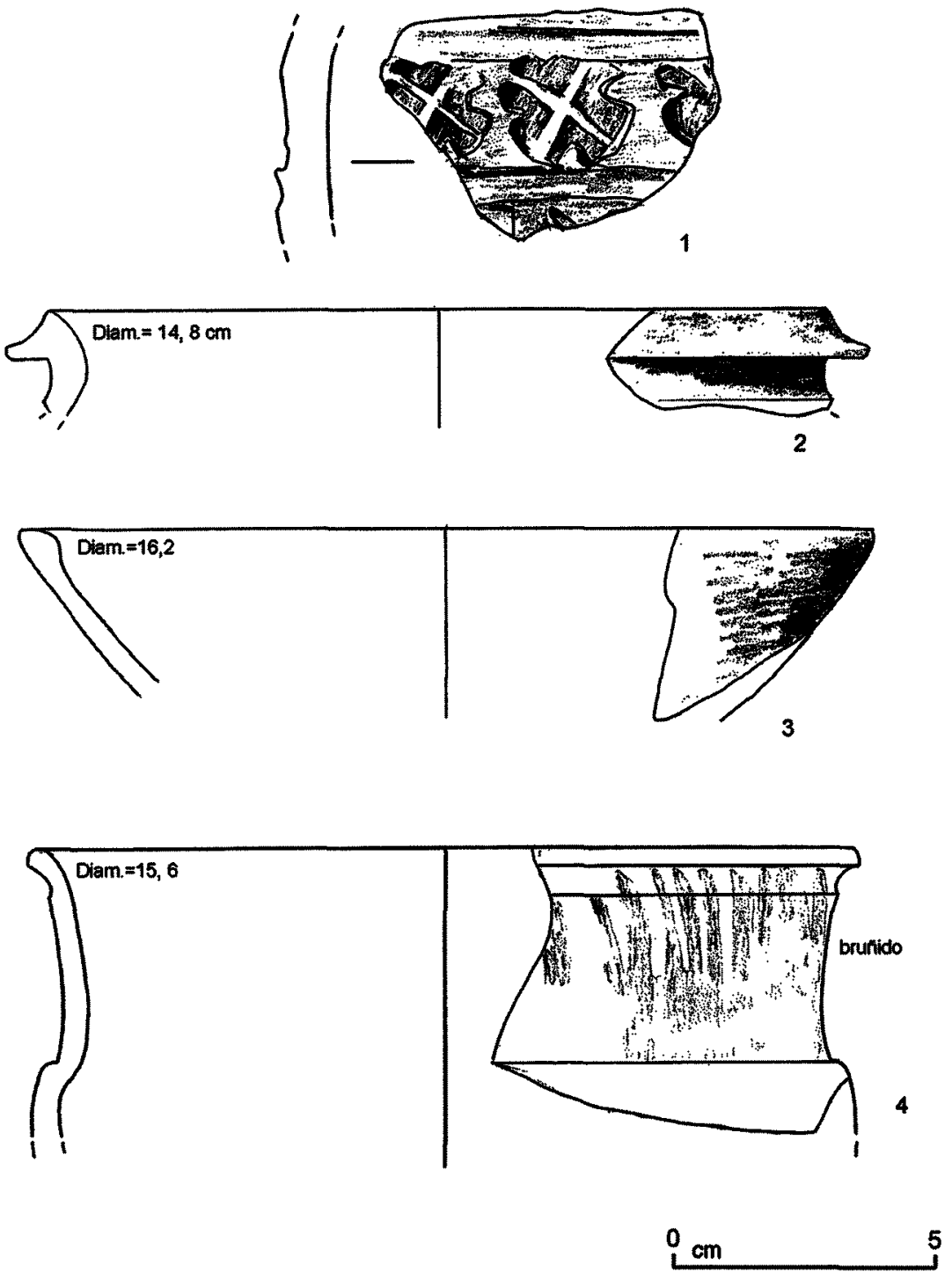

Lamina 17: Fragmentos cerámicos de color gris realizados a torno procedentes del yacimiento Arroyo Culebro. 1: Decoración de estampillas. 
El sílex es más escaso en el conjunto, pero está representado de forma puntual casi siempre en relación con el aprovechamiento directo de los materiales antiguos de arrastre. Así muchas de las piezas presentan roturas de pátina (característico cambio en la textura de la superficie del material, que implica la presencia de intervenciones en momentos cronológicamente distantes). La calidad de este sílex es irregular, tal como son las presentaciones que del mismo aparecen en el contexto litológico inmediato.

Algunas de las piezas ofrecen pátina fluvial, otras en cambio se presentan en estado muy fresco y con huellas de uso. No olvidemos que los materiales que se asentaban sobre niveles de terraza, a partir de lo cuales se ha desarrollado el nivel edáfico, han sido objeto por ello de fuertes alteraciones.

El método de talla se revela como sumamente expeditivo. Los dos núcleos de la colección (uno de ellos dudoso) presentan una búsqueda directa de planos de percusión para la consecución de productos, con una escasa exigencia técnica en la elaboración. Uno de los núcleos presenta además rotura de pátina, que implica probablemente el aprovechamiento de materiales antiguos de terraza, sobre la que se ha aplicado un esquema ligeramente bifacial. No hay en ningún caso búsqueda de alargamiento, aprovechamiento de aristas ni preparación de los puntos de impacto, elementos básicos en las producciones laminares.

La obtención de matrices aprovechables como elementos de hoz es la voluntad que dirige la actividad de talla. En relación con el expeditivo carácter de la producción, no se advierte acondicionamiento térmico del material salvo en una de las piezas (fragmento de lámina), lo que requiere necesariamente la intervención, probablemente ocasional, de tecnologías complejas de producción. Aunque algunas de las piezas presentan huellas de alteración por fuego, esta circunstancia puede ser explicada por causas ajenas al propio proceso de talla.

Están ausentes los procesos de acondicionamiento de talones, siendo éstos generalmente lisos o corticales; tampoco se advierten huellas de acondicionamiento de anversos ni presencia de productos encaminados a dotar al núcleo de una morfología adecuada.

Por tanto, las características técnicas de las matrices sugieren su procedencia de núcleos poliédricos que habrían sido objeto de una escasa programación. Sólo en algunas piezas podrían estar presentes esquemas que implican una vaga pervivencia de la laminación, muy escasa en el conjunto.

El retoque de las piezas presenta un dominio de la técnica de presión. Se aplica de forma unifacial, bifacial, o alterna, en varias ocasiones de modo denticulante. En algún caso se ha llevado a cabo un retoque de reavivado posterior, probablemente una vez enmangados los productos.

Observamos por tanto que los únicos requisitos formales que se impone el tallador son las dimensiones adecuadas; en algún caso se ha recurrido a la técnica del golpe de buril quizás para recortar las piezas facilitando su encaje. Sin embargo la mayoría del material presenta un dorso engrosado, que, aunque sin duda habría dificultado el enmangue, es 
común a otros conjuntos algo más antiguos (El Ventorro; Priego, C. y Quero, S., 1992; Cancho Gordo; Planas Garrido, M., 2000).

Cuando no se consigue la estandarización dimensional pretendida (tímida estandarización formal que apenas lleva asociada un esquema técnico específico), se recurre a la fracturación intencional de las piezas. Así se advierte en algunas de éstas la presencia de alveolos en sus reversos, producto de los golpes que en principio podrían haber servido para su división por fractura en dos mitades. Este sistema habría supuesto una sencilla técnica de consecución de morfologías y tamaños deseados.

Los dientes de hoz de la colección están elaborados básicamente sobre lasca, sin demasiada exigencia técnica; salvo en un caso (dudoso) no se ha advertido en ellos restos de lustre de cereal aunque abunda la presencia de pátinas previas, sobre todo fluviales, en relación con el sistema inmediato de captación de la materia prima.

Sus morfologías son variables ( 1 media luna, 2 de media luna a triangulares, 1 cuadrangular) y presentan el característico dorso engrosado, con retoques que en algún caso (Lámina $18, \mathrm{n}^{\circ}$ ) han sido elaborados sobre yunque (golpeando sobre una plataforma fija) en uno y otro sentido, como se desprende de su bidireccionalidad. El filo es generalmente denticulante (Lámina $18, \mathrm{n}^{\circ} 4,5$ y 7), por presión (Lámina $18, \mathrm{n}^{\circ} 13$ ) o por retoque simple de raedera (Lámina $18, \mathrm{n}^{\circ} 8$ ).

Igualmente fue localizado un fragmento de diente de hoz cuyo origen ha podido estar en la fracturación de una lámina serrada; en todo caso la disposición de la parte activa es diferente en esta pieza que en el resto de la colección. Podría tratarse de un instrumento alargado, a modo de sierra, de múltiples posibilidades funcionales que ha sido posteriormente fracturado en relación con un cambio de funcionalidad.

Una de las piezas podría interpretarse como una raedera/raspador, sobre sílex de escasa calidad con abundancia de alteraciones. En general se advierte, como decimos, una limitada exigencia en la materia prima, que se acerca en muchos casos a variedades opalinas.

Además de estos testimonios procedentes de la excavación, han sido constatados otros hallazgos en las prospecciones desarrolladas sobre el terreno. Así, fue localizado un canto que, además de huellas de arrastre por arado, presenta evidencias claras de pátina de alisamiento; la ausencia de huellas claras de percusión activa desestiman su uso como percutor. El material, cuarzo o cuarcita indicaría quizás una relación con la cercana confluencia del Manzanares con la cuenca del Jarama. Se ha localizado además otro fragmento de cuarcita, pero en todo caso los testimonios son demasiados escasos para sugerir desplazamientos a otros ámbitos.

Es igualmente llamativo (aunque se encuentre fuera de la industria tallada) la presencia de un fragmento de posible colgante/brazalete sobre esquisto micáceo (Lámina 18, $\mathrm{n}^{\circ}$ 1). Presenta huellas de abrasión en la base del mismo y una perforación troncocónica doble realizada de forma independiente a partir de ambas caras del objeto. Para su silueta se ha aprovechado probablemente un canto de morfología apropiada, sin que parezca existir un acondicionamiento periférico específico. 

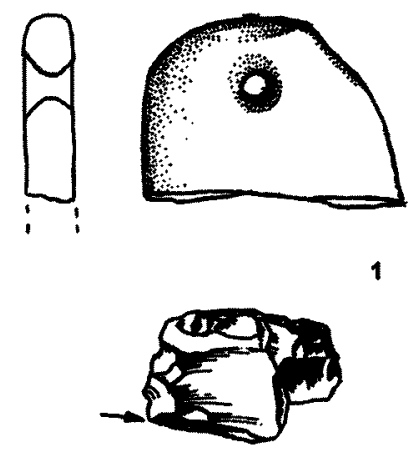

3
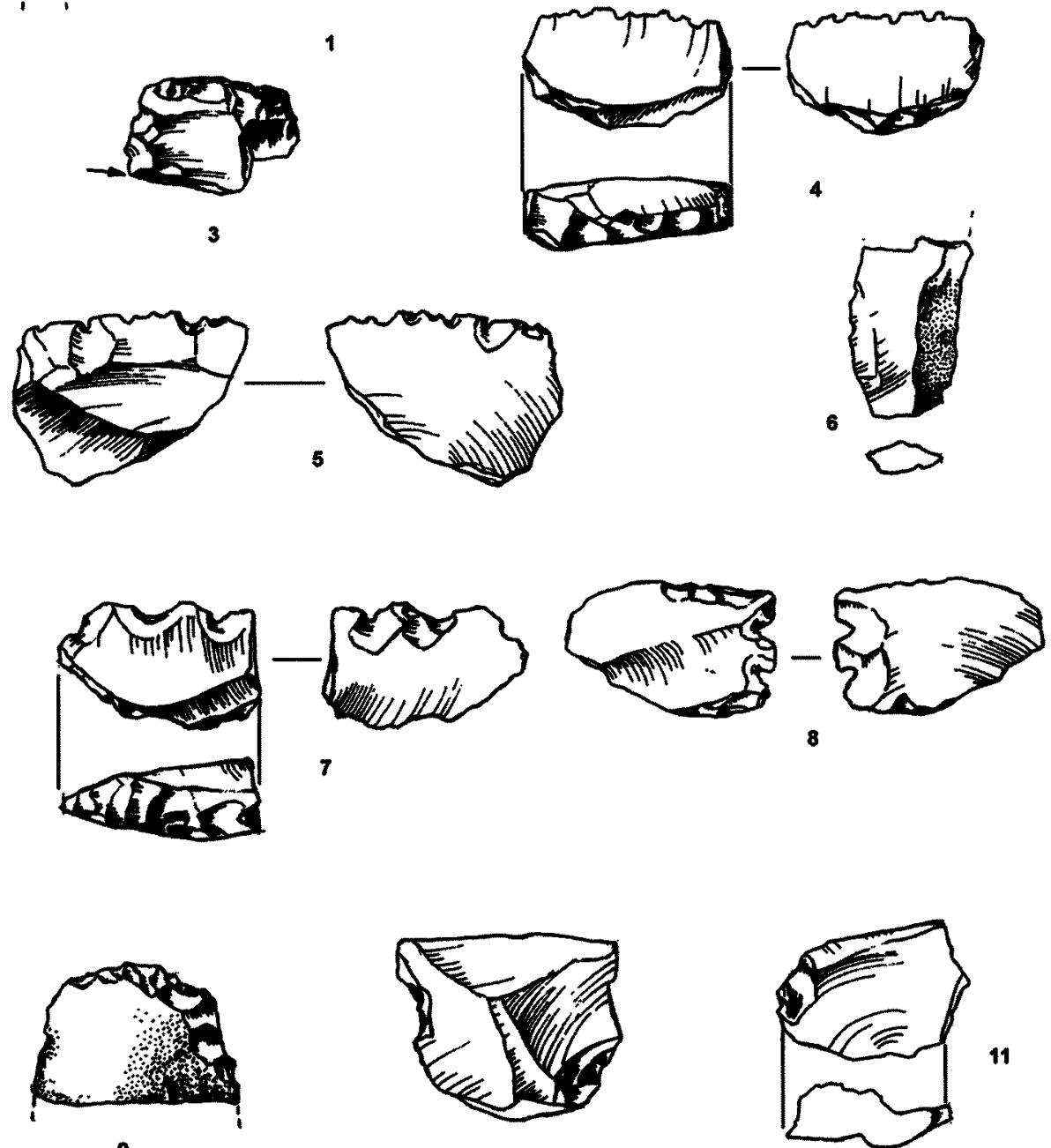

10
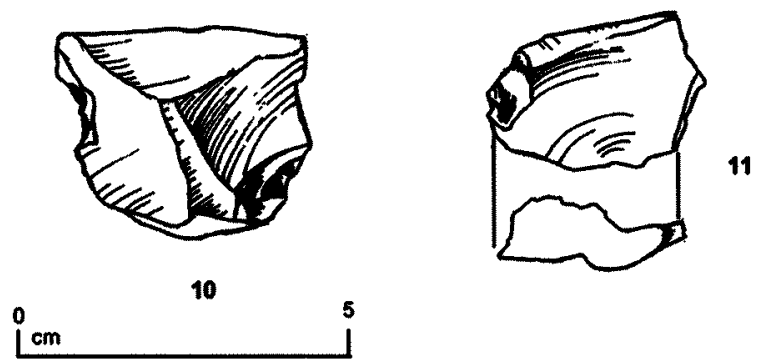

Lámina 18: Industria lítica recuperada en Arroyo Culebro. 
Aproximación al significado del material lítico: En definitiva, la orientación esencial de este conjunto es evidentemente agrícola, faltando otros elementos de utillaje que pudieran conformar una panoplia instrumental paralela. Únicamente, como ya se ha mencionado, ha aparecido una raedera/raspador sobre fragmento térmico.

Cabe preguntarse la causa de esta perpetuación de la actividad de talla en un contexto general de conocimiento metalúrgico. Parece evidente el factor cultural como elemento explicativo, siendo de sobras conocida la tradición de fabricación de trillos a partir de piezas de silex preservada hasta la actualidad en algunos medios rurales.

La talla lítica había seguido siendo floreciente durante el Calcolítico, cuando quizás se registren aún ciertas pervivencias enraizadas en las tradiciones paleolíticas de fabricación, como se evidencia en el cercano yacimiento de El Ventorro; (Priego, C. y Quero, S., 1992). En estas producciones se observa la presencia de dos tradiciones técnicas distintas: la talla laminar y una tradición paralela de producción de soportes lascas a partir de núcleos poliédricos y escasamente estandarizados en los que la única exigencia parece la producción expeditiva de lascas. Estos procesos alternativos a la producción laminar pueden aparecer sin embargo estandarizados, tal como observamos en el yacimiento de El Campo de Fútbol de Preresa, a poca distancia del Arroyo Culebro (Baena, J y Luque, M., 1994), pero presentando una inversión técnica y energética sustancialmente distinta a la de los esquemas leptolíticos. La representación laminar, sin embargo, comienza a empobrecerse (Martínez Navarrete, I., 1979; Asquerino, $M^{2}$ D., 1979), aunque aún se presentan algunos tipos evolucionados tales como las puntas de flecha y las foliáceas. Se produce además en estos momentos una fuerte selección del silex, que es elegido en sus calidades óptimas para la producción laminar (Blasco, C., Baena, J y Recuero, V., 1988-89).

Durante la Edad del Bronce siguen apareciendo algunos ejemplos de presencia laminar en los conjuntos como en el yacimiento del Cancho Gordo; (Planas, M., 2000), siendo muy abundantes en estos contextos, sobre todo en los momentos avanzados del Bronce, los elementos de hoz (yacimientos de la Loma del Lomo, Arenero de Soto), tipos que perpetúan su presencia durante la primera edad del Hierro (Camino de los Pucheros I) (Muñoz, K., 1993). Durante el Calcolítico los dientes de hoz parecían más escasos, tal como se constata en el yacimiento de El Ventorro (op. cit. supr.) o en La Esgaravita (Martínez Navarrete, I., 1979).

El peso de la talla lítica durante la Edad del Hierro parece disminuir quedando, quizás como reducto cultural, limitado al ámbito de lo puramente agrícola. La laminación disminuye; la programación en los núcleos es apenas rastreable y hay un aprovechamiento muy poco selectivo de las rocas locales. La oferta litológica deja de ser un parámetro económico sustancial, tal como lo había sido anteriormente, y se convierte, como en este caso, en una práctica ocasional subsidiaria de actividades artesanales alternativas.

En todo caso, la presencia de restos de talla, algún núcleo aislado y las piezas retocadas apuntan hacia un trabajo in situ de estos elementos, para los que en principio pueden descartarse explicaciones como las que fueron utilizadas en otras piezas arcaizantes aparecidas en contextos cronológicamente recientes (Baena, J. y Carrión, E., 2000). En nuestro caso se atisba la presencia de una cadena operativa muy sumaria, si bien reflejan- 
do un cierto abandono de la técnica de talla como factor de identificación cultural. La talla lítica parece haberse convertido en artesanía menor, accesoria, sólo enfocada a los aspectos más elementales de la economía.

\section{CRONOLOGÍA}

A pesar de la pérdida de información que supone una recuperación de materiales en un contexto tan arrasado, de la ausencia de estratigrafía en el momento de la intervención y de la dificultad existente para delimitar la superficie de los distintos asentamientos diacrónicos, si es que los hubo, el material exhumado nos permite intuir la existencia de una primera ocupación que, posiblemente, se limitó a una pequeña extensión en la zona sur del yacimiento, en el área más próxima al cauce del arroyo Culebro, donde la cerámica a mano es más abundante, incluso no sabemos si exclusiva; dicha ocupación podría pertenecer a la segunda mitad del s. VI a. C., pero desconocemos si después el lugar se abandona temporalmente y se reocupa o, por el contrario, se mantiene habitado sin solución de continuidad. En cualquier caso, los materiales más recientes, que certifican esa presencia humana tardía, se extienden por una superficie más amplia, sin que podamos atestiguar si los restos de suelo de barro localizados pertenecen a estructuras algo más sólidas que las precedentes.

Otros datos temporales complementarios nos los ofrece el conjunto cerámico perteneciente a esta posible segunda fase que, tanto por su decoración como por su morfología nos lleva al siglo $\mathrm{V}$ a. $\mathrm{C}$., momento en el que se produce la iberización de esta zona, coincidiendo con la fase de plenitud del Ibérico levantino, una cronología que parece estar avalada por la comparecencia porcentual de las distintas variedades alfareras y, sobre todo, por las dos fechas de termoluminiscencia obtenidas: $2405+184$ y $2456+195$ B.P. (Rubio, I. y Blasco, C., 2001).

\section{CONSIDERACIONES FINALES}

El yacimiento de Arroyo Culebro es un claro ejemplo de los asentamientos de la Edad del Hierro en esta región del Tajo, hasta la llegada de los primeros indicios de romanización en la zona, mostrando una cierta fidelidad a determinados aspectos tradicionales como es el escaso tamaño, su condición de lugar abierto, sin recintos perimetrales ni evidencias de obras públicas de envergadura y una arquitectura doméstica de escasa envergadura que sigue sin dejar otras huellas, que las de algunos suelos de guijarros o arcilla endurecida.

Frente a esta aparente continuidad, se evidencian síntomas de cambio en una ubicación más alta y alejada del río (Lámina $19, \mathrm{n}^{\circ} 3$ ) que permite un mayor control visual (Lámina $19, \mathrm{n}^{\circ}$ 2) al ocupar las zona interfluviales más elevadas, circunstancia que permite el dominio ocular de dos cauces próximos (Lámina 19, $\mathrm{n}^{\circ}$ 2). La localización de los asen- 


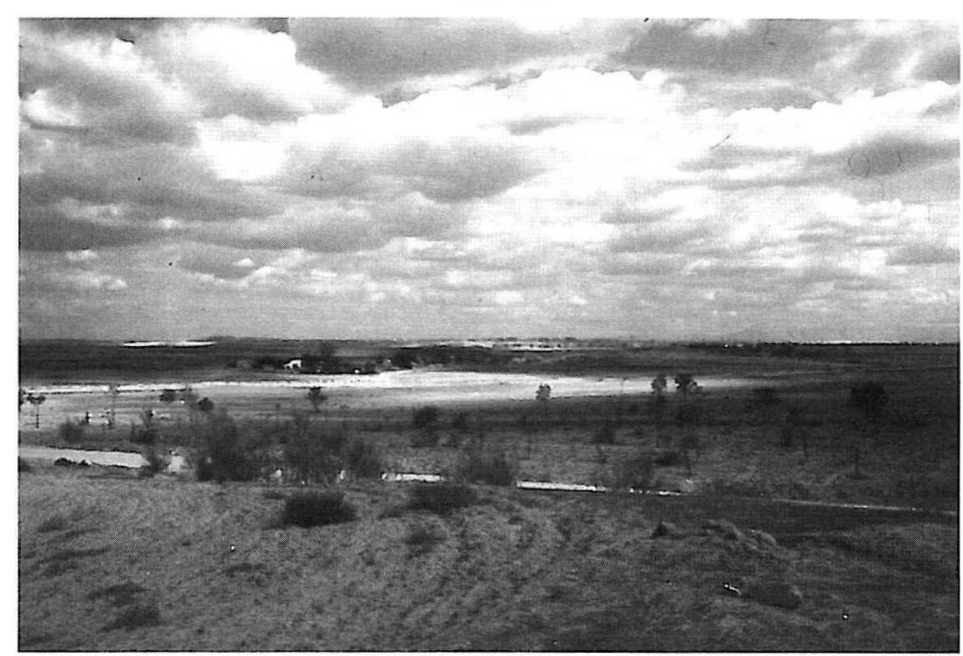

1

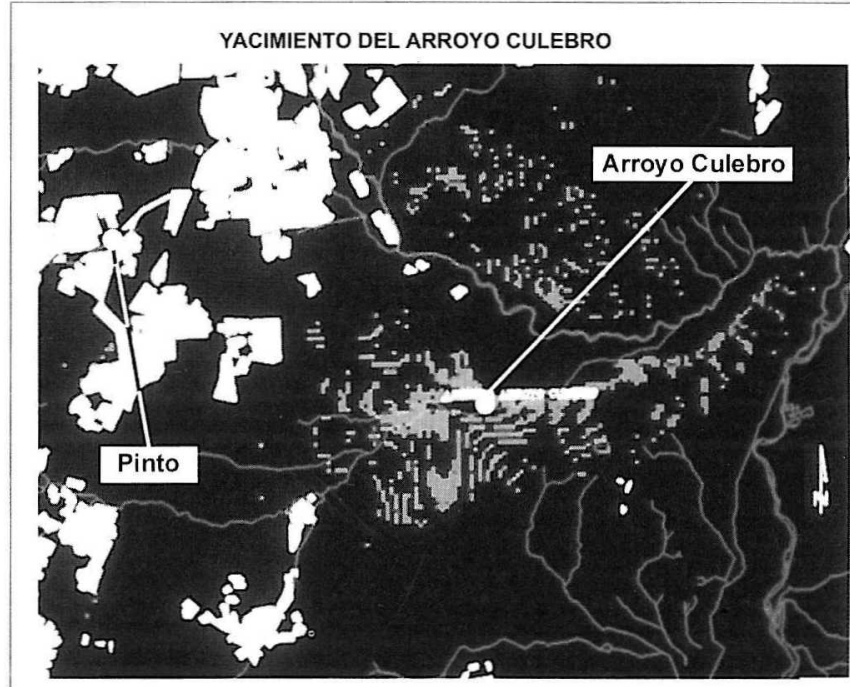

$20 \mathrm{~km}$ aprox. ESCALA 1/50.000

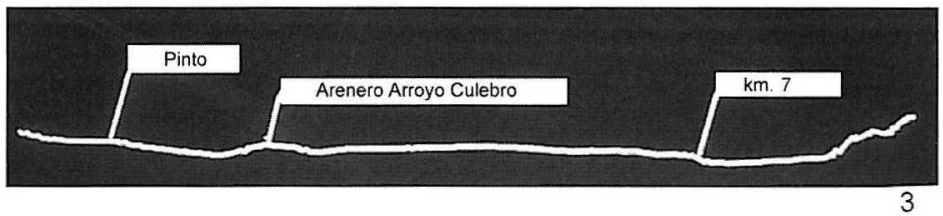

Lámina 19: 1. Vista general del yacimiento de Arroyo Culebro. 2. Polígono de visibilidad de Arroyo Culebro (gris) y de Pinto (blanco). 3. Corte transversal al río Manzanares con la localización del km. 7 perteneciente al Bronce Final (Cogotas I) y los yacimientos de Pinto y Arroyo Culebro de la Edad del Hierro. 
tamientos en los páramos (Lámina $19, \mathrm{n}^{\circ} 1$ ) no es obstáculo para seguir beneficiándose, dentro de la propia área de captación, de las tierras ribereñas más aptas para pastos ricos y para la agricultura de huerta.

Desconocemos la localización de la necrópolis pero no descartamos que estos pequeños asentamientos situados en algunas zonas, como es ésta del curso bajo del Manzanares, a muy poca distancia unos de otros, pudieran compartir un mismo cementerio que podría ser un lugar de referencia de todos ellos, quizás en la Torrecilla, a poca distancia de la confluencia del Culebro en el Manzanares y donde se han exhumado algunas incineraciones (Priego, $M^{a}$ C. y Quero, S. 1978). Sin embargo la evidencia de la inhumación de un perinatal bajo un pavimento doméstico puede ser otro de los rasgos que este yacimiento ejemplariza como característica del mundo carpetano, equiparando algunas de sus prácticas funerarias a las de otros pueblos peninsulares coetáneos.

Por último, no podemos dejar de destacar que los materiales muebles también reflejan esa doble condición de cambio y continuidad que caracteriza a estos grupos de la Edad del Hierro. Concretamente, la artesanía cerámica mantiene el doble sistema de elaboración: a mano y a torno, si bien éste relega, en poco tiempo, a las producciones manufacturadas a porcentajes muy bajos y a usos domésticos que no requieren acabados cuidados (cocina o contenedores de escasa capacidad), mientras que las piezas más selectas (servicios de mesas) o aquellas que por sus proporciones (grandes contenedores) requieren mayor destreza debido a su complejidad, se elaboran con la ayuda del torno, si bien algunas de estas producciones mantienen clara filiación con ejemplares anteriores realizados a mano, son las producciones grises o negras, de superficies bruñidas o, incluso la reiteración de engobes rojos "a brochazos" que podrian ser un recuerdo de las habituales "almagras" del Hierro Antiguo de esta misma zona.

En paralelo, el conjunto vascular de Arroyo Culebro es perfectamente representativo del ámbito carpetano que asimila las características de la cerámica ibérica, pero tomando sólo los motivos más sencillos, repitiéndolos hasta la saciedad, a la par que introduce sobre recipientes, técnica y formalmante ibéricos, acabados distintos y específicos de esta zona como son los engobes cuya dispersión marcan los límites de la Carpetania, tal como lo evidencia el yacimiento alcarreño de Los Morales (Valiente, J 1993) (Lámina 20). Estas producciones de "tipo ibérico" conviven en Arroyo Culebro y, en general en todo su entorno, con los vasos negros de acabados espatulados y decoraciones estampilladas que recuerdan troqueles metálicos, propios de la Meseta norte y, especialmente del ámbito vettón, una dualidad que muestra a las claras la doble esfera de influencia que marcan sus relaciones.

Otro es el caso de la industria lítica que evidencia el imparable declive, iniciado a partir de la Edad del Bronce, ante la imposibilidad de competir con una metalurgia que en estos momentos ha introducido ya el hierro para los aperos y enseres cotidianos y que resulta eficaz y relativamente asequible, sin embargo, como ya se ha apuntado, en su último estadio, la industria lítica mantiene su actividad, al igual que en el Bronce Final y el Hierro Antiguo, exclusivamente, para la realización de elementos de hoz, los últimos productos del trabajo de la piedra tallada que durante toda la Prehistoria se benefició de la gran abundancia de materia prima que ofrecen las terrazas del Manzanares y de sus tributarios entre los que se encuentra el Arroyo Culebro, especialmente pródigo en sílex. 


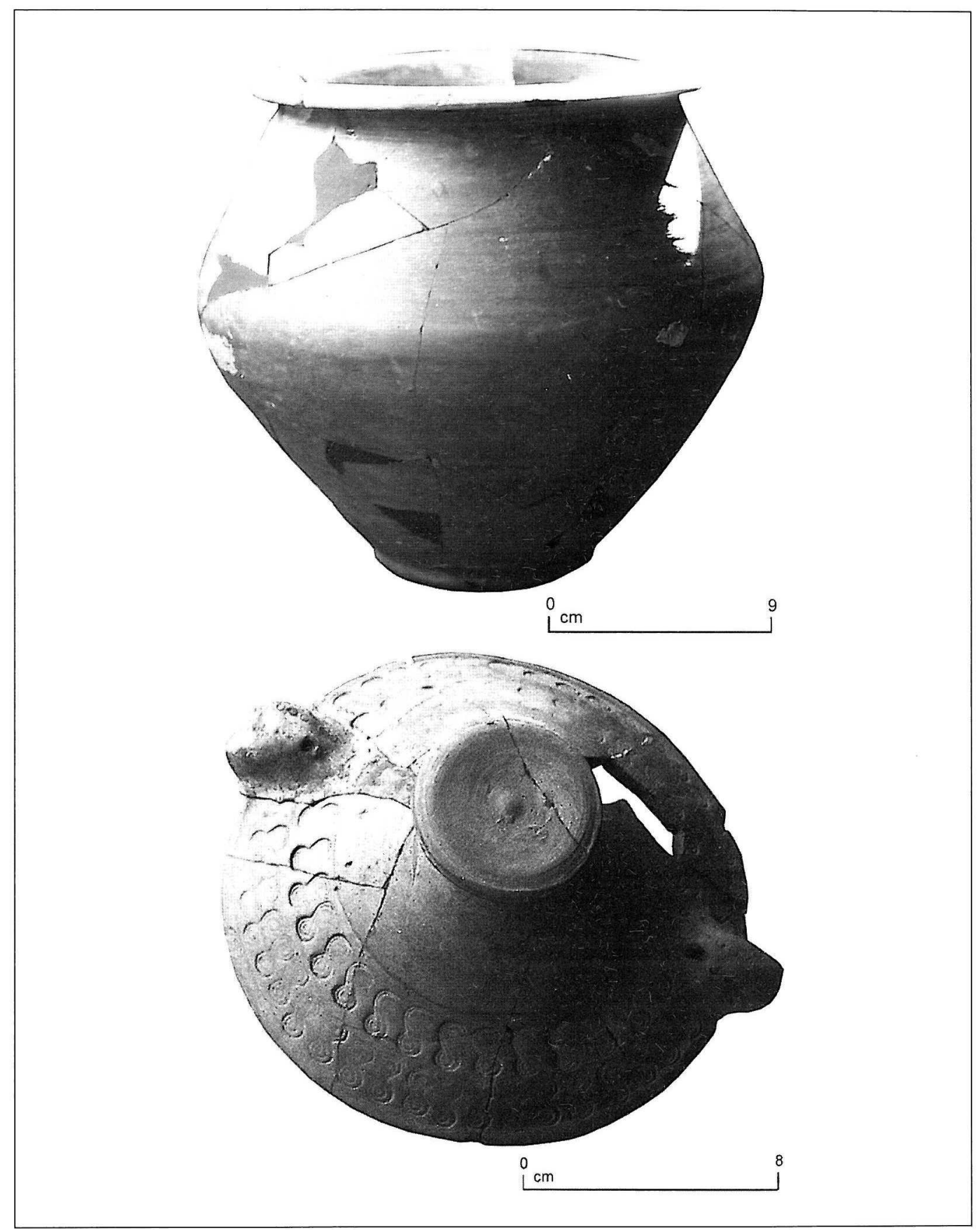

Lámina 20: Uña con decoración "jaspeada" y tapadera de urna de orejetas procedentes del yacimiento de Los Morales (Jadraque, Guadalajara)". 


\section{BIBLIOGRAFIA}

AGUSTÍ, B, ALONSO, N., GARCÉS, I., JUNYENT, E.LAFUENTE, A. y LOPEZ, J. B. (2000): "Una inhumación múltiple de perinatales en la fortaleza de Els Villars (Arbeca, Lleida) y las prácticas de enterramiento en hábitat durante la Primera Edad del Hierro en el Valle del Segre (Cataluña)" En Archéologie de la Mort Archéologie de la tombe au Premier Âge du Fer Actes du XXI Colloque International de l'Association française por l'Étude de l'Âge du Fer Lattes: 305-324.

ASQUERINO, Mª D. (1979): "Fondos de cabaña del Cerro de la Cervera (Mejorada del Campo, Madrid)" Trabajos de Prebistoria, $\mathrm{n}^{\circ}$ 36: 119-150.

BAENA, J. ; CARRIÓN, E. (2000): "La industria lítica" BLASCO, C.; LUCAS, Mª R.(Coord): El yacimiento romano de La Torrecilla: de villa a tugurium. Ediciones UAM, Madrid: 110-114.

BAENA, J.; LUQUE, M. (1994): "La producción lítica durante fases calcolíticas: Análisis del conjunto del yacimiento campaniforme del Campo de Fútbol (Getafe, Madrid)" BLASCO, C. (Ed.): El Horizonte Campaniforme de la región de Madrid en el centenario de Ciempozuelos. Madrid.

BARRIO, J. (1999): La Segunda Edad del Hierro en Segovia (España). Estudio arqueológico del territorio y la cultura material de los pueblos prerromanos. BAR International Series 790. Oxford.

BELTRÁN, A. (1962): "Dos notas sobre el poblado hallstáttico del Cabezo de Monleón: I. La planta. II. Los kernoi" Caesaraugusta 19-20. Zaragoza:7-36.

BLASCO, Mª C. y BAENA, J (1989). "El yacimiento de La Capellana (Pinto, Madrid). Nuevos datos sobre las relaciones entre las costas meridionales y la submeseta sur durante la Primera Edad del Hierro" CuPAUAM, 16, Madrid: 211-231

BLASCO, C. BAENA, J. y RECUERO, V (1988-89): "Novedades sobre el horizonte campaniforme en la región de Madrid" Zephyrus, XLI-XLII, Salamanca: 199-227

BLASCO, Ma C. y BARRIO, J. (1986). "Excavaciones en dos nuevos asentamientos prehistóricos en Getafe (Madrid)" N.A.H., 27 Madrid: 75-142.

BLASCO, $M^{a}$ C., LUCAS, $M^{a}$ R. y ALONSO, $M^{a}$ A. (1991): "Excavaciones en el poblado de la Primera Edad del Hierro del Cerro de San Antonio (T.M. Madrid)" Arqueología, Paleontología y Etnografia, 2. Comunidad de Madrid: 7-189.

BLASCO, $M^{a}$ C., SÁNCHEZ-CAPILLA, Ma L. y CALLE, J (1988): "Madrid en el marco de la Primera Edad del Hierro de la Península Ibérica" CuPAUAM, 15, Madrid: 139-182.

ESCUDERO, Z. (1995): "Nuevos estudios sobre el poblado vacceo de "El Soto de Medinilla" (Valladolid)" En Delibes y otros (eds.) Arqueología y Medio Ambiente. El Primer Milenio A.C. en el Duero Medio. Valladolid 179-217

CUADRADO, E. (1973): "El castro carpetano de Yeles (Toledo)" XII CNArq, Zaragoza 355-362.

GÓMEZ. A. y SANZ, C. (1993): "El poblado vacceo de Las Quintanas, Padilla de Duero (Valladolid): Aproximación a su secuencia estratigráfica" En Romero y otros (eds.) Arqueologia Vaccea., Valladolid: 335-370. 
MARTÍNEZ NAVARRETE, I. (1979): "El yacimiento de La Esgaravita y la cuestión de los fondos de cabaña" Trabajos de Prebistoria, $\mathrm{n}^{\circ}$ 36: 83-118.

MENA, P. (1985): Catálogo de cerámicas de necrópolis de la Edad del Hierro del Museo de Cuenca. Cuenca

MUÑOZ, K. (1993): "El poblamiento desde el Calcolítico a la Primera Edad del Hierro en el valle medio del río Tajo" Complutum, $\mathrm{n}^{\circ}$ 4: 321-336.

MUÑOZ. K. y J. ORTEGA (1996): "La transición Primera-Segunda Edad del Hierro en el Bajo Henares. Las cabañas de "Los Pinos" (Alcalá de Henares, Madrid)". Actas del V Encuentro de Historiadores del Valle del Henares. Guadalajara: 31-43.

NIETO, G., SÁNCHEZ MESEGUER, J.L. y POYATO, Mª C. (1980): Oreto I. EAE 114, Madrid.

PLANAS GARRIDO, M. (2000): El yacimiento del Cancbo Gordo (La Cabrera, Madrid): Aplicación de un Sistema de Información Geográfica. Memoria de Licenciatura inédita. Universidad Autónoma de Madrid.

PRIEGO, C. (1986). "Edad del Hierro I y II: El yacimiento de Puente de la Aldehuela" Villa de Madrid, año XXIV, 1986-III y IV, núm. 89-90. Madrid: 120-135.

PRIEGO, C.; QUERO, S. (1978): "Prehistorica madrileña: Una obra maestra de la orfebrería. El brazalete de oro de La Torrecilla (Getafe)" Villa de Madrid. Año XVI, 1978-II, nüm. 59. Madrid: 17-23.

PRIEGO, C., QUERO, S. (1992): El Ventorro. Un poblado prebistórico de los primeros albores de la metalurgia. Estudios de Prehistoria y Arqueología Madrileñas, $\mathrm{n}^{\circ} 8$.

RODANÉ, J Ma y RAMÓN, N. (1996): "Cerámica de la Edad del Bronce de la cueva del Moro de Olvena". Bolskan. 13: La Cueva del Moro de Olvena II. Huesca: 39-132.

RUBIO , I y BLASCO, $\mathrm{M}^{\mathrm{a}} \mathrm{C}$. (2001): "La cronología del Hierro Antiguo en el área de Madrid a partir de los datos obtenidos por Termoluminiscencia" Actas Congresso Arqueología peninsular 99- Vol V. Braga.

VALIENTE CÁNOVAS, S. (1994): Excavaciones arqueológicas en "El Cerrón" Illescas (Toledo). Toledo.

VALIENTE MALLA, J. (1995): "Los Morales" (Jadraque, Guadalajara) y los límites de la Carpetania" Wad-al Hayara, 22, Guadalajara: 33-61. 